\title{
MORPHOGENETICALLY ACTIVE SCAFFOLD FOR OSTEOCHONDRAL REPAIR (POLYPHOSPHATE/ALGINATE/N,O-CARBOXYMETHYL CHITOSAN)
}

\author{
W.E.G. Müller*, M. Neufurth, S. Wang, E. Tolba, H.C. Schröder and X. Wang \\ ERC Advanced Investigator Grant Research Group at the Institute for Physiological Chemistry, University Medical \\ Center of the Johannes Gutenberg University, Duesbergweg 6, D-55128 Mainz, GERMANY
}

\begin{abstract}
Here we describe a novel bioinspired hydrogel material that can be hardened with calcium ions to yield a scaffold material with viscoelastic properties matching those of cartilage. This material consists of a negatively charged biopolymer triplet, composed of morphogenetically active natural inorganic polyphosphate (polyP), along with the likewise biocompatible natural polymers $\mathrm{N}, \mathrm{O}$ carboxymethyl chitosan $(N, O-C M C)$ and alginate. The porosity of the hardened scaffold material obtained after calcium exposure can be adjusted by varying the preprocessing conditions. Various compression tests were applied to determine the local (nanoindentation) and bulk mechanical properties (tensile/compression test system for force measurements) of the $\mathrm{N}, \mathrm{O}$-CMC-polyPalginate material. Determinations of the Young's modulus revealed that the stiffness of this comparably water rich (and mouldable) material increases during successive compression cycles to values measured for native cartilage. The material not only comprises viscoelastic properties suitable for a cartilage substitute material, but also displays morphogenetic activity. It upregulates the expression of genes encoding for collagen type II and aggrecan, the major proteoglycan within the articular cartilage, in human chondrocytes, and the expression of alkaline phosphatase in human bone-like SaOS-2 cells, as revealed in RT qPCR experiments. Further, we demonstrate that the new polyPbased material can be applied for manufacturing 3D solid models of cartilage bone such as of the tibial epiphyseal plate and the superior articular cartilage surface. Since the material is resorbable and enhances the activity of cells involved in regeneration of cartilage tissue, this material has the potential to be used for artificial articular cartilage implants.
\end{abstract}

Keywords: Cartilage, polyphosphate, regenerative medicine, $\mathrm{N}, \mathrm{O}$-Carboxymethyl chitosan, tissue engineering.

*Address for correspondence:

Prof. Dr. W.E.G. Müller

ERC Advanced Investigator Grant Research Group at Institute for Physiological Chemistry, University Medical Center of the Johannes Gutenberg University Mainz, Duesbergweg 6, D-55128 Mainz, Germany,

Telephone number: +49 6131-39-25910

Fax number: +49 6131-39-25243

E-Mail address: wmueller@uni-mainz.de

\section{Introduction}

Articular cartilage, a hyaline cartilage of a thickness of 2-4 mm, is a highly specialised tissue who's function is to reduce joint friction at the extremities of the long bones (reviewed in: Fox et al., 2009). This tissue is lacking any blood vessels, nerves, or lymphocytes. It is characterised by a compact and massy extracellular matrix (ECM), into which cells - the chondrocytes - are only rarely embedded. Besides water, the ECM is composed of collagen, especially type II, which provides the material with the required shape and strength, and proteoglycans through which the matrix acquires resistance to mechanical stress (Poole et al., 2001). The proteoglycans retain most of the water in the ECM and, by that, provide and maintain the mechanical properties of the cartilage (Weber et al., 2015). Articular cartilage has only a limited capacity for repair. This has been attributed to the absence of vasculature and, as a consequence, the lack of a trafficking path - reducing the possibility of distribution and migration, especially of progenitor cells, from the blood or the bone marrow (Vinatier et al., 2009).

The cartilage is divided into the following four zones (Fuller and Ghadially 1972; Fox et al., 2009; Johnstone et al., 2013); superficial, middle, deep and the zone of calcified cartilage. The thin superficial tissue zone, comprising 10$20 \%$ of the cartilage thickness, protects the deeper layers from mechanical shear stresses. It is composed of collagen fibres of type II and IX that run parallel to the articular surface (Fig. 1) and harbour flattened chondrocytes. The middle, transitional zone, encompassing 40-60\% of the total cartilage volume, contains proteoglycans and thicker collagen fibrils. Those fibrils are organised obliquely, and contain chondrocytes in a scattered density. The deep zone ( $\approx 30 \%$ of the articular cartilage) showing the strongest resistance to compressive forces is traversed by collagen fibrils that are arranged in a perpendicular manner to the articular surface. This zone has a high proteoglycan content, and simultaneously a low water concentration. There, the chondrocytes are arranged in a columnar orientation, parallel to the collagen fibres. Finally, the zone of calcified cartilage, which comprises only scarce hypertrophic chondrocytes, and, besides protein, contains phosphate and carbonate of different degrees of crystallinity (Duer $e t$ al., 2009). The calcified cartilage forms the cartilage-bone [periosteum] interface (Hoemann et al., 2012), the site which is rich in mesenchymal stem cells (MSC) (Mara et al., 2011). The MSC give rise to both chondrocytes and osteoblasts (Vinatier et al., 2009; Kang et al., 2015). Recent results show that the periosteum chondrocytes represent a major source of osteoblasts and, by that, contribute to the endochondral bone formation in vivo (Zhou et al., 2014). 


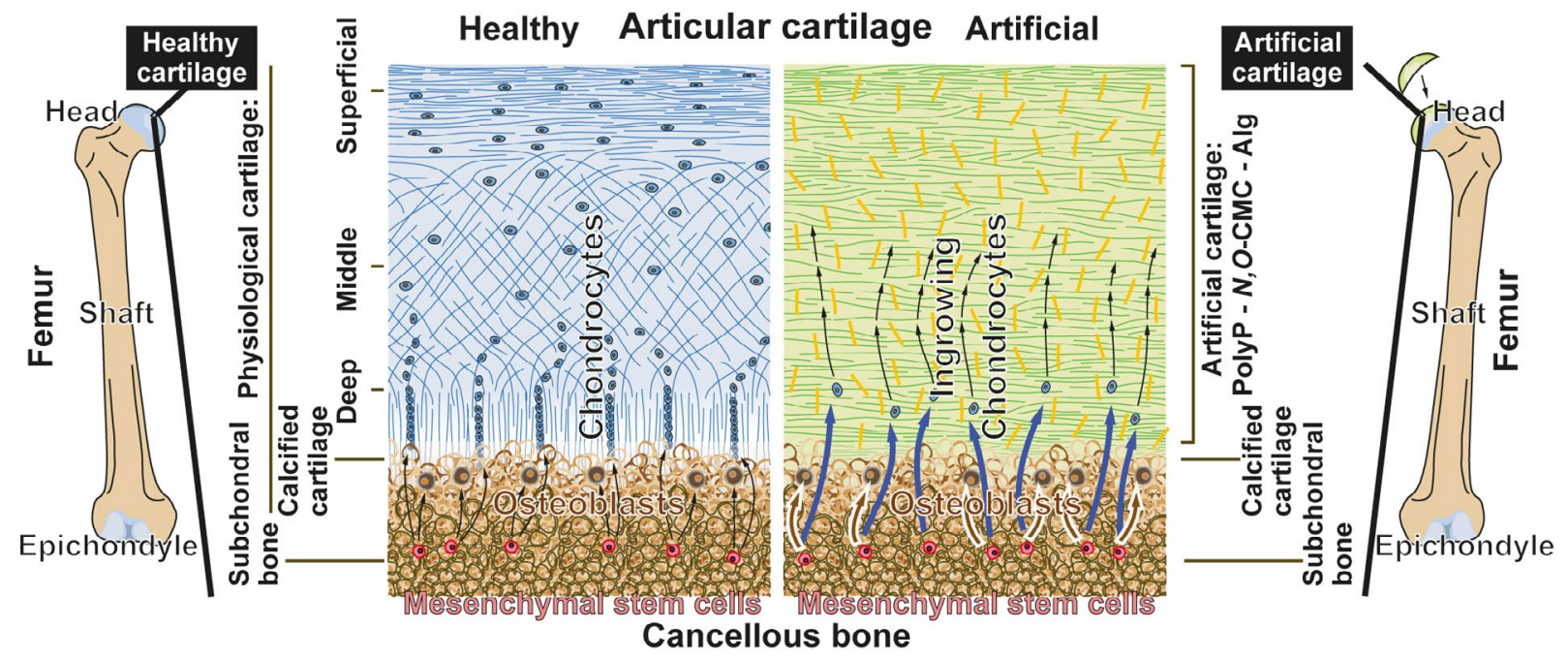

Fig. 1. Schematic diagram of osteochondral tissue. (Left) Histology of the transition zones between the cancellous bone and cartilage; the different zones are marked. The ingrowing chondrocytes form a fibrous collagen filament into which the glyco-proteinaceous matrix is deposited. (Right) Proposed implantation of the artificial scaffold formed from polyP, alginate and $\mathrm{N}, \mathrm{O}-\mathrm{CMC}$. It is highlighted that the mesenchymal stem cells differentiate both to bone cells which deposit the calcified cartilage, layered on top of the subchondral bone and to chondrocytes which migrate into the artificial cartilage material, where they release collagen and proteoglycan.

In the last three decades attempts have been made to exploit (bio)material-assisted, synthetic or bioinspired polymeric materials, or even biomimetic and biological materials as cartilage substitutes (reviewed in: Johnstone et al., 2013; Seo et al., 2014; Grässel and Lorenz, 2014). Besides tissue transplantation, strategies targeting repair of chondral or osteochondral tissue have been driven by the requirements that the scaffolds are biocompatible, biodegradable and meet the mechanical properties and conditions, as well as the pore structure of the ambient tissue. Biodegradable synthetic polymers, e.g. aliphatic polyesters, in different formulations have been applied to osteochondral scaffolds. Due to poor surface activity and cell affinity, those materials have been blended and copolymerised, such as polyvinyl alcohol with polycaprolactone (Shafiee et al., 2011). Since those polymeric scaffolds have been proven to comprise insufficient mechanical characteristics, e.g. low stress resistance, the organic polymers have been reinforced with inorganic materials, such as metals or ceramics (Navarro et al., 2008).

Surely, cell sources, modified by molecular and genetic manipulations, will contribute to successful future biological solutions in the field of development of a genuine functional tissue engineered cartilage substitute (Chung and Burdick, 2008). However, the regulatory requirements to be overcome are extraordinary. Focusing on biomaterials, the development lines for a cartilage substitute started from inert and non-biodegradable hydrogel materials, e.g. agarose, or alginate (Chang et al., 2001), and aimed at fabricating biologically active materials (reviewed in: Johnstone et al., 2013; Seo et al., 2014). The latter line of development of three-dimensional cartilage-like, or imitating matrices, either followed the highly organised hierarchical, filamentous structure of the cartilage or scaffold-free constructs. Based on the three-dimensional fibre organisation of the natural cartilage; polymers, such as collagen, chitosan and hyaluronic acid, have been applied to reach the desired structural stability and distinctive compression-resistance properties (Mow et al., 1992). Those hybrid materials have been further biologised by physisorption of proteins/peptides on their surfaces (Ma et al., 2002) or by inorganic deposits, such as hydroxyapatite (HA) (Kato et al., 1996). Scaffold-free artificial cartilage constructs using natural alginate (Hauselmann et al., 1992) or hyaluronan (Goa and Benfield, 1994), have been reinforced with collagen sponges (Nehrer et al., 1998), fibrin (Sims et al., 1998), or synthetic polymers such as poly(lactic acid) (Freed et al., 1994).

The hitherto fabricated artificial articular cartilage materials show some significant success in repairing animal osteochondral defects, by producing fibrocartilaginous repair cartilage, a stage which can be further improved by adding cells to the implanted matrices (see: Johnstone et al., 2013). To continue in this line of thinking, we fabricated a biomaterial that allows the cells to invade the artificial material. Cells, able to migrate into a polymeric material follow a gradient of growth factor(s), e.g. transforming growth factor $\beta$ (TGF- $\beta$ ) (Johnstone et al., 1998), as well as structural elements, allowing them to adhere, such as collagen or Arg-Gly-Asp (RGD)-tagged peptides (Neufurth et al., 2015). Furthermore, the biomaterial must allow the migrating cells to form niches into which they can settle; preferentially, they should find their proper pore configurations by dissolving the biomaterial, enabling them to tunnel through. Stimulated by available data indicating that platelet-rich plasma/platelet-rich fibrin are effective substrates and scaffolds for growth of MSC in fibrocartilage-like tissue and, in turn, a promising source for osteochondral tissue regeneration (Wakitani et al., 
2007; Seo et al., 2013), we studied in detail the effect of the major inorganic constituent of platelets, polyphosphate (polyP) (see: Morrissey et al., 2012). In these cells, polyP is present in a concentration of $0.74 \mathrm{nmol} / 10^{8}$ platelets, corresponding to $\approx 1.1 \mathrm{mM}$. The chain length of this polymer in vivo can range from three to more than $1000 \mathrm{P}$ residues (Rao et al., 2009). In addition, polyP is present in larger amounts in osteoblast(-like) cells (Leyhausen et al., 1998). This polymer is not biologically inert, but induces the expression of genes in bone(-related) cells required for the differentiation of MSC to osteoblasts, e.g. bone morphogenetic protein 2 (BMP2), (reviewed in: Wang et al., 2014a). Recently we have established that the water soluble polyanion polyP, with the cationic counterion $\mathrm{Na}^{+}$, and the soluble organic polymer alginate form in the presence of $\mathrm{Ca}^{2+}$ stable complexes, qualifying this biomaterial as a promising artificial bone implant material (reviewed in: Wang et al., 2015). This self-assembled hydrogel network, built of polyP and alginate has been successfully reinforced with $N, O$-carboxymethyl chitosan and has even proven to be a promising hard implant material in in vivo studies (Müller et al., 2015c). The hardness of the scaffold can be adjusted to the biomechanical requirements of the environment by a controlled exposure to $\mathrm{Ca}^{2+}$.

In the present study, we describe the formulation for a bioscaffold material, composed of the physiological polymer polyP, as well as the biocompatible natural polymers, $\mathrm{N}, \mathrm{O}$-carboxymethyl chitosan $(\mathrm{N}, \mathrm{O}$-CMC) and alginate, that has the potential to be used as an artificial articular cartilage material. This scaffold matches the biomechanical properties of cartilage and elicits morphogenetic activity, both for the human bone-like SaOS-2 cells (Pautke et al., 2004) and human chondrocytes (Prins et al., 2014), since it upregulates the gene expressions of the alkaline phosphatase (ALP) in SaOS-2 cells and of collagen type II (COL-II) as well as of aggrecan in chondrocytes. Finally, it is demonstrated that the new scaffold can be used for moulding of soft tissue regions, the superior articular cartilage surface and the epiphyseal plate, within the epiphysis and the metaphysis of the tibia.

\section{Materials and Methods}

\section{Materials}

Na-polyP with an average chain length of $\approx 40$ phosphate units was obtained from Chemische Fabrik Budenheim (Budenheim, Germany). The peptide $\mathrm{NH}_{2}-$

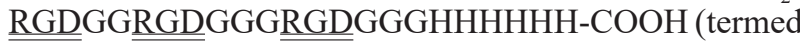
His/Gly-tagged RGD) has been chemically synthesised by Coring System Diagnostix (Gernsheim, Germany).

\section{Preparation of the $\mathrm{N}, \mathrm{O}$-CMC-polyphosphate-alginate material \\ $\mathrm{N}, \mathrm{O}$-carboxymethyl chitosan $(\mathrm{N}, \mathrm{O}-\mathrm{CMC})$ was prepared as described (Müller et al., 2015a). The basic N,O-CMC- polyphosphate-alginate hydrogel was derivatised from chitosan (\#C3646; Sigma, Taufkirchen, Germany), as outlined (Müller et al., 2015a). In brief, $1 \mathrm{~g}$ of $N, O-C M C$ was dissolved in $20 \mathrm{~mL}$ sterile $0.9 \% \mathrm{NaCl}$, at ambient}

temperature while stirring, yielding a $5 \%$ solution. After complete dissolution $0.4 \mathrm{~g}$ of Na-polyP $(2 \%$ [w/w; final concentration]) was added and stirred until homogeneous. Finally, 1 g of sodium alginate (\#W201502; SigmaAldrich) was added and again stirred until the solution reached a smooth texture. The His/Gly-tagged RGD peptide was added, at a concentration of $30 \mu \mathrm{g} / \mathrm{mL}$, to the basic scaffold components ( $\mathrm{N}, \mathrm{O}-\mathrm{CMC}$, polyP and alginate) prior to the crosslinking with $2.5 \%$ [w/v] aqueous $\mathrm{CaCl}_{2}$ solution. The ready-made hydrogel was either directly used for the preparation of artificial cartilage or stored at $4{ }^{\circ} \mathrm{C}$ in a sealed container until needed.

\section{Preparation of artificial cartilage scaffolds}

Two different types of artificial cartilage scaffolds were prepared. First, an A-Type scaffold was fabricated from freshly prepared basic hydrogel; the second type, B-Type scaffold, was prepared from the basic hydrogel after a storage period of $2 \mathrm{~d}$ at $4{ }^{\circ} \mathrm{C}$. Both types of scaffolds were processed, in a moulding procedure, to tissue-like modules (used for the biomechanical studies) or the hydrogel was spread directly onto a given surface (for cell culture experiments). Subsequently, the modules or the coated surfaces were hardened by complete immersion in an aqueous $2.5 \%(170 \mathrm{mM}) \mathrm{CaCl}_{2}$ solution at $37^{\circ} \mathrm{C}$, overnight. Finally, the artificial cartilage scaffolds were washed twice for 5 min with sterile phosphate buffered saline (PBS) and then stored submersed in PBS, in a container at $4^{\circ} \mathrm{C}$.

\section{Determination of the mechanical properties: nanoindentation}

The stiffness of the artificial cartilage scaffolds (local Young's modulus) was measured in PBS by using the Piuma nanoindenter ferruled optical fibre system (Optics11, Amsterdam, The Netherlands) (Chavan et al., 2011). For each sample ten independent measurements were performed at ten different sites.

\section{Determination of the mechanical properties: compression testing}

The overall mechanical properties of the cartilage scaffolds (bulk Young's modulus or compressive modulus) were measured on standardised cylindrical material samples $(11 \times 5 \mathrm{~mm})$, using a "MultiTest 2.5-xt Force Testing System" equipped with a Load Cell (100 N) unit (Mecmesin Ltd., Slinfold, UK). All data were recorded continuously at a frequency of $50 \mathrm{~Hz}$ using the Emperor XT Force software (Mecmesin Ltd.). To determine the unconfined compressive strength, a force of $25 \mathrm{~N}$ was applied to the samples and kept for $60 \mathrm{~s}$. Subsequently, an unloading period $(0 \mathrm{~N})$ followed for $300 \mathrm{~s}$. This cycle was repeated five times. The resulting force-displacementtime data were used to calculate the bulk Young's modulus of the material for the different cycles according to the following equation: $\mathrm{E}$ [Young's modulus] equals to $\sigma$ [stress] $/ \varepsilon$ [strain], whereby $\sigma=$ force $(\mathrm{N}) /$ area $\left(\mathrm{mm}^{2}\right)$ and $\varepsilon=\Delta \mathrm{L}[$ difference in length $](\mathrm{mm}) / \mathrm{L}_{0}[$ initial length $](\mathrm{mm})$.

For the generation of the creep-recovery-curves a constant load of $2.5 \mathrm{~N}$ was applied to the samples and held for $30 \mathrm{~min}$. Subsequently, the recovery period followed 
during which the force of $0 \mathrm{~N}$ was held for $10 \mathrm{~min}$. All data for the creep-recovery-curves were recorded at a frequency of $50 \mathrm{~Hz}$ and used to calculate the stress $(\sigma)$ and the strain ( $\varepsilon$ ) as described (Mansour, 2003); sample sizes $11 \times 5 \mathrm{~mm}, 25 \mathrm{~N}$ for $60 \mathrm{~s}$, followed by $0 \mathrm{~N}$ for $300 \mathrm{~s}(5$ replications). Where indicated, comparative measurements were performed with cartilage samples from domestic pigs, obtained from a local butcher.

\section{Water content}

To determine the water content of the respective cartilage samples, the material was cut to slices of almost identical dimensions. After removal of the superficial liquid the specimens were deep frozen at $-80^{\circ} \mathrm{C}(60 \mathrm{~min})$ and lyophilised overnight (Sentry 2.0 lyophiliser; SP Scientific, Warminster, PA). Then the dry weight was determined and the $\%$ water content was calculated.

\section{Light microscopy analyses}

Digital light microscopy studies were performed using a VHX-600 Digital Microscope (Keyence, Neu-Isenburg, Germany) equipped with a VH-Z25 zoom lens. The surface texture was sized with the "Easy, on-screen 3D profile measurement" (Keyence) program. The lyophilised samples were inspected with a digital microscope (VHX-1000, Keyence Deutschland GmbH, Neu-Isenburg, Germany). The ingrowth of the chondrocytes was documented after removal of the medium/serum after gentle shaking. Five independent experiments were performed.

\section{Cultivation of human SaOS-2 cells and human chondrocytes}

The human osteogenic sarcoma cells SaOS-2 cells (Pautke et al., 2004) were cultured in McCoy's medium (BiochromSeromed, Berlin, Germany) that was supplemented with $2 \mathrm{mM} \mathrm{L}$-glutamine, $15 \%$ heat-inactivated foetal calf serum (FCS), 100 units $/ \mathrm{mL}$ penicillin and $100 \mu \mathrm{g} /$ $\mathrm{mL}$ streptomycin (Wiens et al., 2010a). The cells were incubated in 24-well plates (diameter of $16 \mathrm{~mm}$; \#CLS3516; Sigma, Taufkirchen, Germany) at $37^{\circ} \mathrm{C}$. The cultures were started with $1 \times 10^{4}$ cells/well in a total volume of $1.5 \mathrm{~mL}$. Where indicated, the cultures were first incubated for a period of $3 \mathrm{~d}$ in the absence of the mineralisation-activating cocktail (MAC), comprising $5 \mathrm{mM} \beta$-glycerophosphate, $50 \mathrm{mM}$ ascorbic acid and $10 \mathrm{nM}$ dexamethasone to induce biomineralisation (Wiens et al., 2010b). Then, the incubation of the cultures was continued for an additional $7 \mathrm{~d}$ in the absence or presence of the MAC. The scaffold slices ("B-Type scaffold") were added to each well at the beginning of the experiments. Every third day, the culture medium was replaced by fresh medium/serum and - where indicated - with MAC.

Human articular chondrocytes were purchased from Lonza (Walkersville, MD). After thawing the vial of frozen cells (normal human articular chondrocyte cells; NHAC$\mathrm{Kn}$ ), the cells were transferred to the chondrocyte growth medium (Lonza; \#CC-4409), supplemented with $15 \%$ FCS, and cultivated in 6-well plates at an initial density of $5 \times 10^{4}$ cells/well. Confluency was reached after 6-7 d. Chondrocytes used were at a passage number no higher than 4 (Guo et al., 1989).
For testing the cartilage specimens, $\approx 2 \mathrm{~mm}$ thick slices, with a diameter of $\approx 15 \mathrm{~mm}$, were inserted into the wells; prior to use they were treated with $70 \%$ ethanol for $5 \mathrm{~min}$. Then, the cells were seeded at a density of $2-3 \times 10^{4}$ per well, directly on the top of each sample. After an attachment period of $15 \mathrm{~min}, 1 \mathrm{~mL}$ of medium/serum was added to each well and the plates were transferred to the incubator and cultivated as indicated under "Results".

\section{Growth onto the scaffolds}

After the respective period of incubation the cell culture medium was removed and the loosely attached SaOS-2 cells were aspirated and the cartilage specimens were washed once with PBS. The samples were fixed with precooled $70 \%$ ethanol at $-20{ }^{\circ} \mathrm{C}$ overnight. After washing once with PBS for $5 \mathrm{~min}$ each the samples were stained by incubation in $5 \mu \mathrm{M}$ DRAQ5 (BioStatus Ltd., Shepshed, UK) in $1 \times$ PBS for $30 \mathrm{~min}$. Inspection and photo documentation of the stained samples were performed in an Evos ${ }^{\mathrm{TM}} \mathrm{FL}$ digital fluorescence microscope with activated $\mathrm{Cy}^{\circledR} 5$ light cube (Fisher Scientific $\mathrm{GmbH}$, Schwerte, Germany) selecting an absorbance of $650 \mathrm{~nm}$ and an emission wavelength of $680 \mathrm{~nm}$ (blue).

\section{Cell viability (metabolic activity) assay}

$\mathrm{SaOS}-2$ cells, as well as chondrocytes, were seeded into the 48-well plates (\#CLS3548 Sigma; Corning/Costar culture plates) and cultured for $3 \mathrm{~d}$ in McCoy's medium/15\% FCS (SaOS-2 cells) or chondrocyte growth medium (chondrocytes). Two parallel series of experiments were performed. Either the cells were cultured in the absence of scaffold slices or incubated onto the "B-Type scaffold". Then, after a $3 \mathrm{~d}$ incubation period, the metabolic activity of the cells was assessed with 3-[4,5-dimethyl thiazole-2yl]-2,5-diphenyl tetrazolium (MTT; \#M2128, Sigma) as described (Wang et al., 2014b). Ten parallel experiments each were performed.

\section{Reverse transcription-quantitative real-time PCR analyses}

The reverse transcription-quantitative real-time polymerase chain reaction (RT-qPCR) was applied to determine the gene expression level of both the alkaline phosphatase $(A L P)$ in SaOS-2 cells and collagen type I (COL-I) in chondrocytes. The cells were seeded either directly onto the culture plates, or were incubated onto the "B-Type scaffold" slices. The SaOS-2 cells remained in the medium/ serum for $3 \mathrm{~d}$ and were subsequently incubated in the absence or presence of the MAC for $7 \mathrm{~d}$. The chondrocytes were incubated in the medium for $7 \mathrm{~d}$. Then the cells were collected and the RNA was isolated, which was then subjected to RT-qPCR (Wiens et al., 2010b). The following primer pairs, matching the respective human $A L P$, human COL-II and human aggrecan genes were used: ALP [alkaline phosphatase; NM_000478.4] fwd:

5'-TGCAGTACGAGCTGAACAGGAACA-3'

$\left[\mathrm{nt}_{1141}\right.$ to $\left.\mathrm{nt}_{1164}\right]$ and rev:

5'-TCCACCAAATGTGAAGACGTGGGA-3' $\left[\mathrm{nt}_{1418}\right.$ to $\mathrm{nt}_{1395}$; product size of $278 \mathrm{bp}$;

COL-II [collagen type II, alpha 1 (COL2A1), transcript variant 1; NM_001844] fwd: 
5'-TCCATTCATCCCACCCTCTCAC-3' nt $_{4755}$ to $\mathrm{nt}_{4776}$ ] and rev: 5'-TTTCCTGCCTCTGCCTTGACC-3' $\left[\mathrm{nt}_{4902}\right.$ to $\left.\mathrm{nt}_{4882} ; 148 \mathrm{bp}\right]$;

and aggrecan [NM_001135.3] fwd:

5'-CCTCTGCATTCCACGAAGCTAACC-3'

$\left[\mathrm{nt}_{6772}\right.$ to $\left.\mathrm{nt}_{6795}\right]$ and rev:

5'-TGCCTCTGTCCCCACATCACTG-3' [ $\mathrm{nt}_{6917}$ to

$\left.\mathrm{nt}_{6896} ; 146 \mathrm{bp}\right]$.

The GAPDH gene [glyceraldehyde 3-phosphate

dehydrogenase; NM_002046.5] fwd:

5'-CCGTCTAGAAAAACCTGCC-3' $\left[\mathrm{nt}_{929}\right.$ to $\left.\mathrm{nt}_{947}\right]$ and rev: 5'-GCCAAATTCGTTGTCATACC-3' $\left[\mathrm{nt}_{1145}\right.$ to $\mathrm{nt}_{1126} ; 217 \mathrm{bp}$ ] was used as reference.

The RT-qPCR reaction was performed as outlined (Wiens et al., 2010b) using an iCycler (Bio-Rad, Hercules, CA, USA). The mean $\mathrm{C}_{t}$ values and efficiencies were calculated using the iCycler software (Bio-Rad); the estimated PCR efficiencies were in the range of 93$103 \%$. Expression levels of the respective transcripts were correlated to the reference gene to determine relative expression, as described (Wiens et al., 2010a).

\section{Moulding of the artificial scaffolds to the hard tibia bone regions}

The soft tissue around a tibia from a young lamb ( $\approx 5$ months) was removed mechanically. Afterwards, the bone was defatted with acetone (Roth, Karlsruhe; Germany), dried at $37{ }^{\circ} \mathrm{C}$ and then immediately used for cartilage reconstruction procedure. The epiphysis, with the protruding intercondylar eminences, was removed from the metaphysis along the cartilage-like epiphyseal plate. Using this tibia specimen, two artificial cartilagelike layers were moulded; first, the cartilage surface layer of the epiphysis (the superior articular cartilage surface) and second the cartilage-like epiphyseal plate. In the first phase of the modelling process, the remaining bony parts were scanned using a laser-based 3D-scanner with $500 \mu \mathrm{m}$ resolution (MakerBot Digitizer; MakerBot Industries, Brooklyn, NY). For each bone part, ten scans were run and combined together using the MakerWare software in order to obtain the final computer model. The 3D-models of the bones were stored in a STL file format and processed with the SolidWorks 2014 software (Dassault Systèmes, Vélizy-Villacoublay, France). Using the latter software, the respective casting forms (representing the superior articular cartilage surface cartilage-like epiphyseal plate) were designed by subtraction of the desired structures from a solid block. This block then was split into two units and channels for the flow of the hardening solution were added. The ready designed moulds were produced by a 3D-printing process using the Zprinter 450 (3DSystems, Rock Hill, SC, USA), according to the manufacturer's instructions. Subsequently, additional moulding forms were prepared by shaping the respective bone surface with a two component polymerising plastic material, Technovit 3040 (Heraeus Kulzer, Wehrheim, Germany). For the fabrication of the artificial cartilage samples, the readymade basic hydrogel was injected within the cavities of the respective moulds by using a $10 \mathrm{~mL}$ syringe without a needle attached. Directly after injection, the moulds were submersed in the $2.5 \% \mathrm{CaCl}_{2}$ hardening solution. In the experiments using two-part moulds, the moulds were closed prior to submersion in $2.5 \% \mathrm{CaCl}_{2}$ solution. In a third approach, the basic hydrogel was injected directly on top of the metaphysis. Subsequently, the epiphysis was placed onto the hydrogel under low pressure; then the specimen was transferred to the hardening solution. The respective samples were incubated in the hardening solution for 1-3 d, depending on the thickness of the sample. After incubation, the samples were washed twice using physiological saline and manually cleaned from the excess of the hardened hydrogel. The final samples were stored at $4{ }^{\circ} \mathrm{C}$ until further analyses.

\section{Statistical analysis}

After finding that the respective values follow a standard normal Gaussian distribution and that the variances of the respective groups are equal, the results were statistically evaluated using the independent two-sample Student's $t$-test (Petrie and Watson, 2013). The generation time (number of cell doublings per given incubation period [3 d]) of the cells was calculated according to Powell (1956).

\section{Results}

\section{Cartilage scaffold}

The basic material, the hydrogel, used for the fabrication of the scaffold consists of the negatively charged polymers $N, O-C M C$, polyP and alginate. After dissolving to a homogeneous jelly-like material the hydrogel can subsequently be processed, after exposure to $\mathrm{CaCl}_{2}$, to a harder, more solid scaffold, as described under "Materials and Methods". While the basic composition of the hydrogel remains unchanged, the porosity of the final scaffold can be adjusted by varying the pre-processing period. Exemplarily, two time points have been selected, in the A-Type scaffold the hydrogel was immediately hardened with $\mathrm{CaCl}_{2}$, while a storage period of $2 \mathrm{~d}$ was used for the fabrication of the B-Type scaffold, prior to the $\mathrm{CaCl}_{2}$ treatment. The "A-Type scaffold" shows a smoother surface texture with a porosity of around $0.2 \mu \mathrm{m}$ (Fig. $2 \mathrm{~A}$ ), while the "B-Type scaffold" is more coarse and rough with pores of about $0.8 \mu \mathrm{m}$ (Fig. 2B).

\section{Cartilage scaffold: Mechanical characterisation}

For the determination of the mechanical properties of the scaffolds, several compression tests were performed using both a nanoindenter and a tensile/compression test system for force measurements. The stiffness of the artificial cartilage scaffolds, the bulk Young's modulus, was determined for the "A-Type scaffold" and for the "B-Type scaffold", using the force testing system, and found to be significantly different between the two scaffolds. In general, the "A-Type scaffold" shows a higher Young's modulus and by that is stiffer, compared to the "B-Type scaffold". While after a single compression cycle the "A-Type scaffold" had a stiffness of $1.02 \mathrm{MPa}$, the corresponding "B-Type scaffold" gave a value of $0.89 \mathrm{MPa}$ (Fig. 3A). After successive compression cycles, the values of the Young's modulus for both "A-Type scaffold" and "B-Type scaffold" 

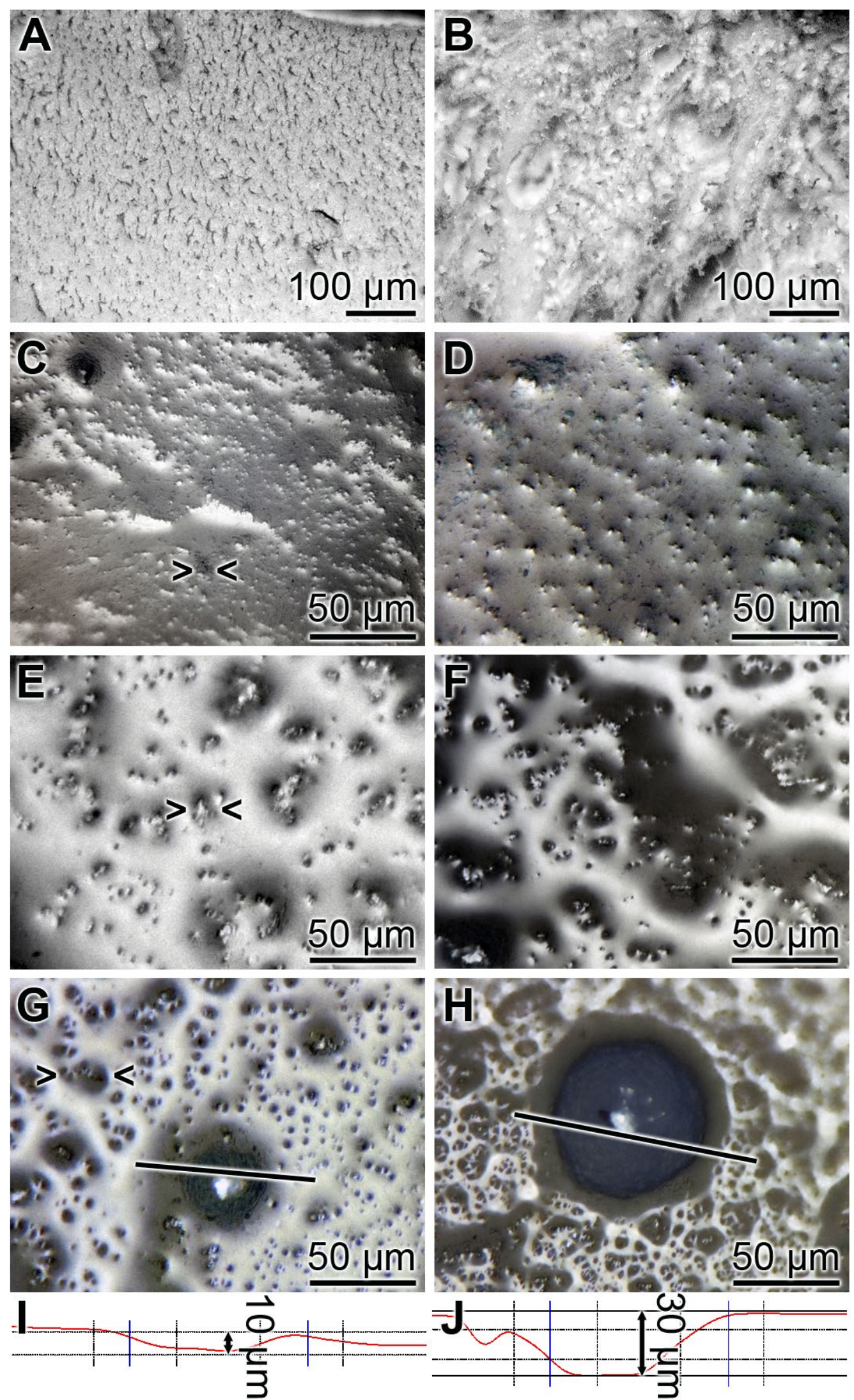

Fig. 2. Artificial cartilage scaffold, prepared from N,O-CMC, polyP and alginate. Two types were studied; "A-Type scaffold" (A, C, E, G), exposed immediately to $\mathrm{CaCl}_{2}$, and "B-Type scaffold" that was fabricated from the hydrogel, after a pre-processing period of $2 \mathrm{~d}(\mathbf{B}, \mathbf{D}, \mathbf{F}, \mathbf{H})$; digital optical microscopic images. (A and $\mathbf{B})$ The scaffold prior to the seeding of the cells. Chondrocytes were grown onto scaffold specimens $(\approx 2 \mathrm{~mm}$ thick; diameter of $\approx 15 \mathrm{~mm})$ placed into in 24-well plates. After an incubation period of $2 \mathrm{~d}(\mathbf{C}$ and $\mathbf{D}), 4 \mathrm{~d}(\mathbf{E}$ and $\mathbf{F})$ or $6 \mathrm{~d}(\mathbf{G}$ and $\mathbf{H})$ the specimens were removed, after gentle rotating, and inspected using an optical microscope. Some holes into which cells were assembled are marked $(><)$. The textures of the surfaces from $\mathbf{G}$ and $\mathbf{H}$ (marked with a line) were assessed by the "Easy, on-screen 3D profile measurement" software (I and $\mathbf{J})$. 

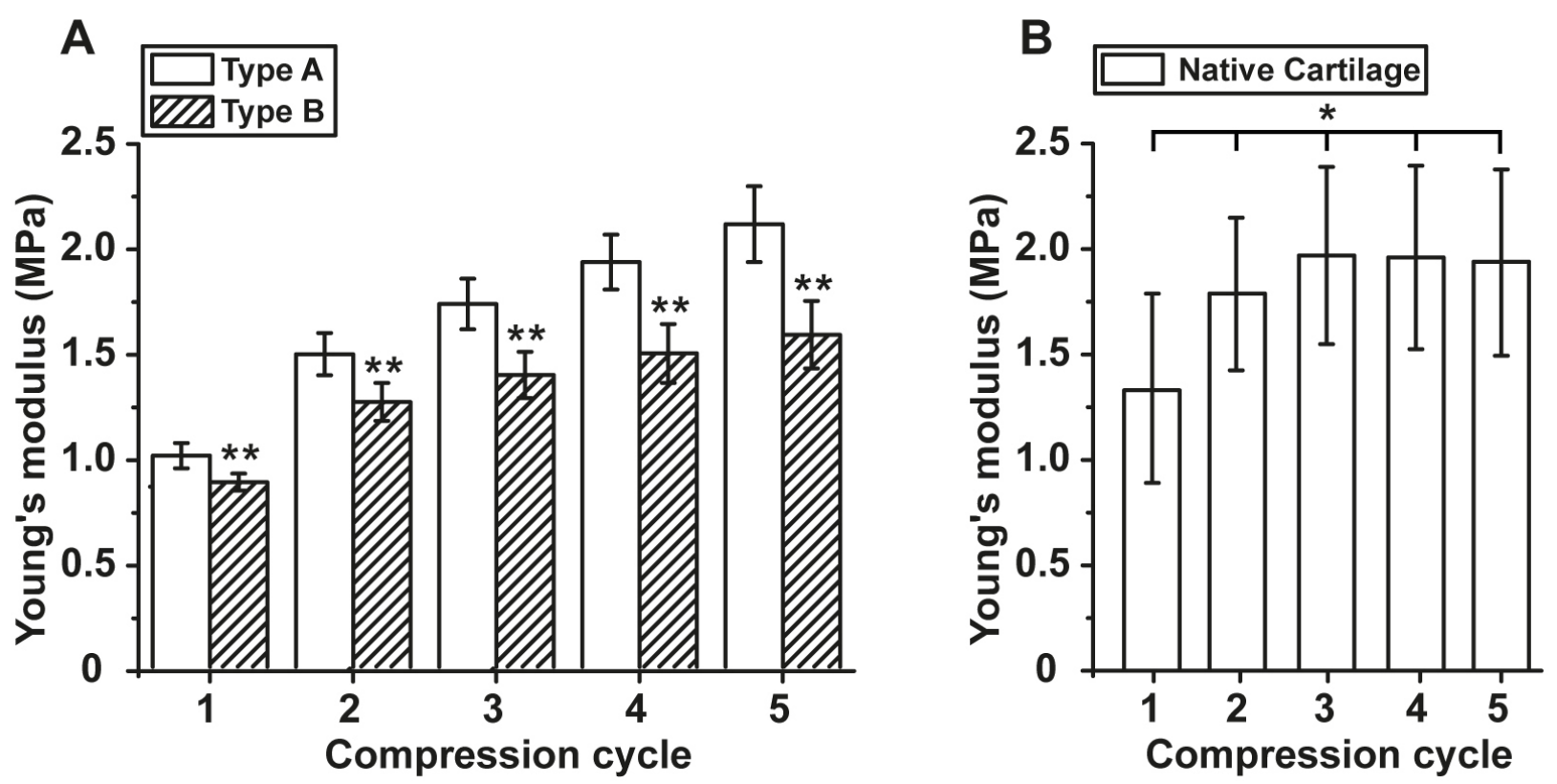

Fig. 3. Mechanical testing of (A) "A-Type scaffold" and "B-Type scaffold" and (B) native cartilage. The bulk Young's modulus was calculated for each of the five compression cycles. The measurements were performed with ten independent samples $(n=10)$. Error bars represent \pm SD. The $p$-values (in A) were calculated between the "A-Type scaffold" and the "B-Type scaffold" materials for a given compression cycle $(* * p<0.01)$. In B the $p$-value $(* p<0.02)$ was determined pairwise between the compression behaviour at cycle 1 (reference point) and the other cycles.
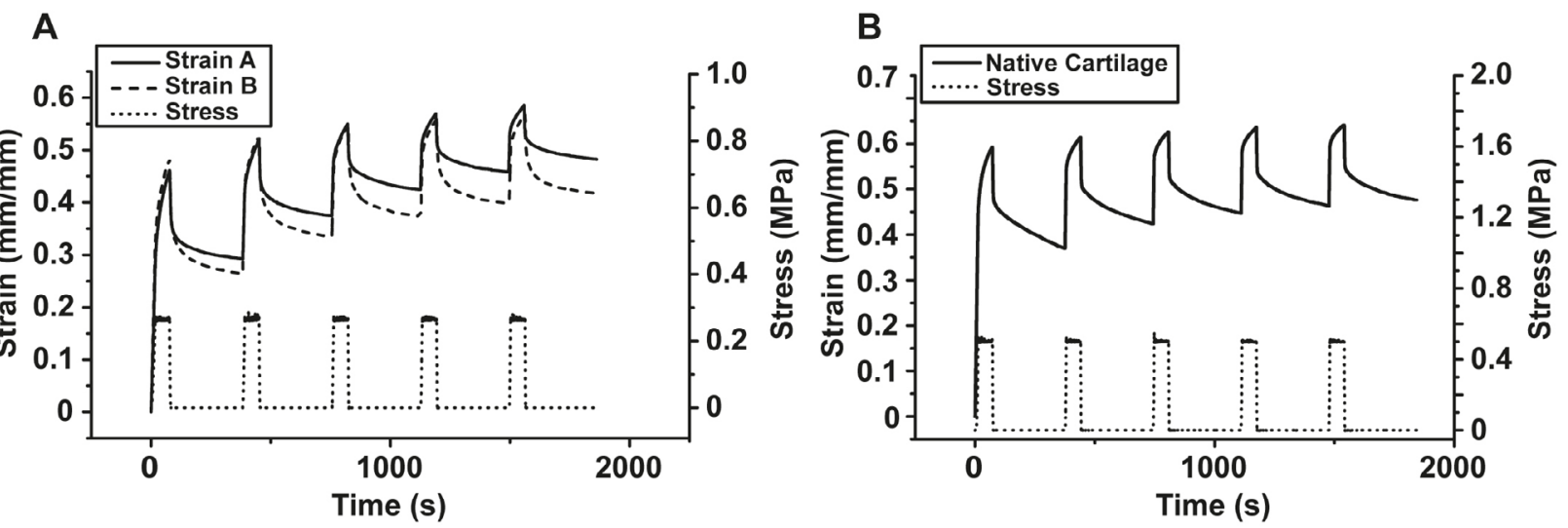

Fig. 4. Multiple strain recordings. (A) Individual strain/time records for the "A-Type scaffold" (termed strain A) as well as the "B-Type scaffold" (strain B). The specimens were exposed to a force of $25 \mathrm{~N}$ for $60 \mathrm{~s}$, followed by an unloading period of $300 \mathrm{~s}$ (dotted line [bottom]). The individual loading/unloading tracings for "A-Type scaffold" (strain A; solid line) as well as "B-Type scaffold" (strain B; broken lone) for the five consecutive stress exposures are shown. (B) A similar recording from a native pig cartilage.

increase and reach values of $2.18 \mathrm{MPa}$ and $1.55 \mathrm{MPa}$, respectively, for samples after the fifth compression cycle. This increase in the stiffness is, at least during the first compression cycles, attributed to the loss of water from the scaffold. In comparison, the Young's modulus for human cartilage shows values of around $1 \mathrm{MPa}$ (compression) (reviewed in: Pal, 2014). An almost identical pattern of the stiffness to "A-Type scaffold" and "B-Type scaffold", has been determined for native cartilage from pig (Fig. 3B). This material also shows an increasing stiffness during 5 compression cycles, starting from 1.3 MPa (first cycle) to $\approx 2.0 \mathrm{MPa}$ (subsequent cycles).

The individual representation of five strain-time graphs for "A-Type scaffold" and "B-Type scaffold" is shown in
Fig. 4A. The material was exposed to a force of $25 \mathrm{~N}$ for $60 \mathrm{~s}$, followed by a load relief of $0 \mathrm{~N}$ for $300 \mathrm{~s}$. During the progress of five consecutive compression cycles of $60 \mathrm{~s}$ duration (force: $25 \mathrm{~N}$ ) the more porous "B-Type scaffold" shows a pronounced recovery response compared to the "A-Type scaffold", indicating that the first material is more elastic. With an increment of the cycle number the Young's moduli increase, reflecting a decrease in the elasticity. This property is attributed initially to a loss of water from the scaffold, followed by a deformation of the architecture of the scaffold material. In turn, this finding reflects a decrease of the overall viscoelastic properties of the material during the course of the loading/unloading treatment. This conclusion is in agreement with the bulk Young's moduli 

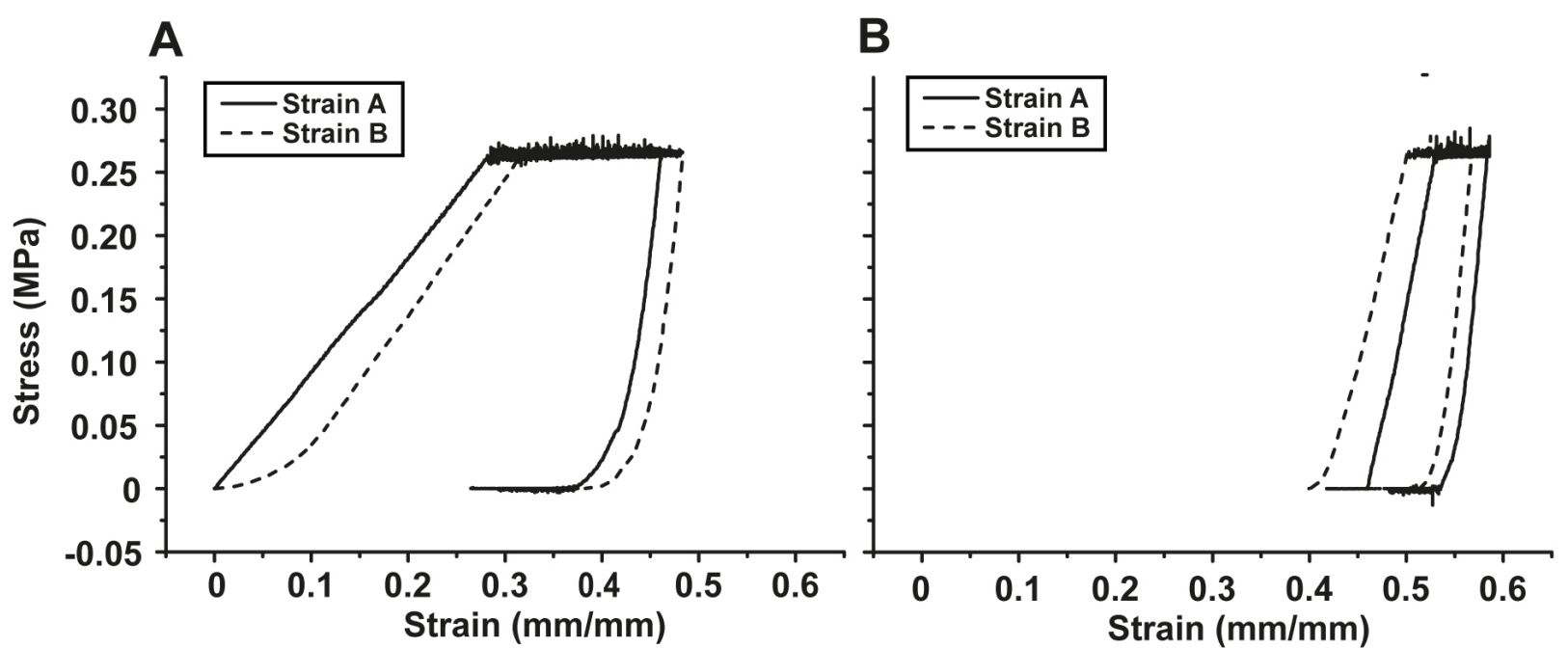

Fig. 5. Stress-strain curves for the two scaffolds, "A-Type scaffold" and "B-Type scaffold", recorded during (A) the first and (B) the fifth compression cycle.
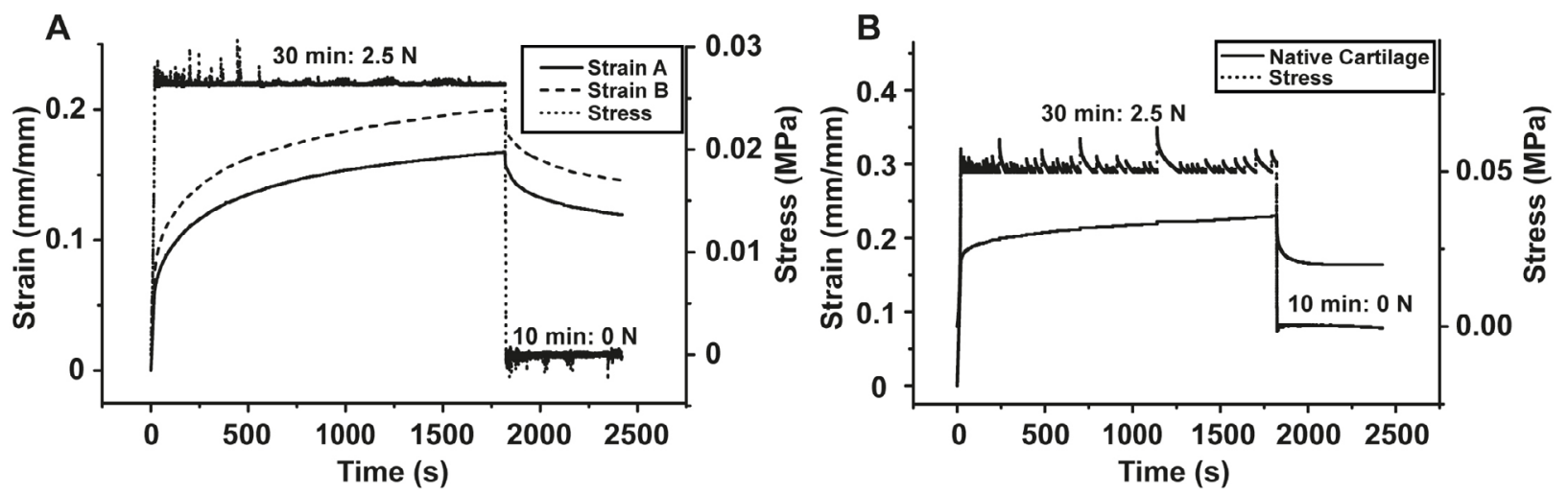

Fig. 6. Representative creep behaviour for "A-Type scaffold" and "B-Type scaffold". The specimens were subjected to a constant compressive stress for $30 \mathrm{~min}(2.5 \mathrm{~N})$, followed by a removal of the stress and recoding the strain changes over another $10 \mathrm{~min}$.

(E-moduli), retrieved for the respective compression cycles (Fig. 3). In comparison, five consecutive compression cycles have been performed with pig cartilage (Fig. 4B). Basically, the traces recorded show principally the same characteristics as the one determined for the artificial scaffold. It is noticeable that the increment of the pig cartilage strain is more pronounced with $0.58 \mathrm{~mm} / \mathrm{mm}$ (first compression) to $0.62 \mathrm{~mm} / \mathrm{mm}$ (fifth cycle), compared to the increase seen in the artificial material with $0.47 \mathrm{~mm} /$ $\mathrm{mm}$ (first cycle) to $0.55 \mathrm{~mm} / \mathrm{mm}$ (fifth cycle).

The shapes of the stress-strain curves (Fig. 5) indicate the typical nonlinear viscoelastic or viscoelastic-plastic behaviours, with delayed recoveries upon unloading. Additionally, irreversible deformations are observable as indicated by the incomplete recovery. A comparison of the respective stress-strain curves between the compression cycle one (Fig. 5A) and five (Fig. 5B) shows distinct differences. In cycle one (Fig. 5A), a strong initial deformation during the loading phase is seen for both material types, reflecting both the porous structure and the higher fluid content of the materials. During loading, the fluid is squeezed out from the samples; for the more porous material "B-Type scaffold" the deformation is stronger compared to the "A-Type scaffold". The load period shows a marked creep behaviour for both material types. During the unloading period, the two material types disclose a similar delayed recovery which is incomplete. The stress-strain curves for compression cycle five (Fig. 5B) are markedly different. The initial deformation upon loading is much less compared to cycle one, which is ascribed to the reduction of the water content of the two samples occurred during the preceding four compressions. Likewise, the creep response of both material types is less distinct. The recovery behaviour upon unloading is more distinct than in cycle one, for both material types; for the "B-Type scaffold" it is almost complete.

A likewise, different creep behaviour is characteristic for "A-Type scaffold" and "B-Type scaffold" (Fig. 6A). Both material samples were loaded with a force of $2.5 \mathrm{~N}$ for $30 \mathrm{~min}$. Then the samples were allowed to recover for $10 \mathrm{~min}$ with a force of $0 \mathrm{~N}$. Both material types show biphasic creep-recovery curves with incomplete recovery upon unloading. In agreement with the stress-strain curves (Fig. 5), the deformation of the "B-Type scaffold" is more 

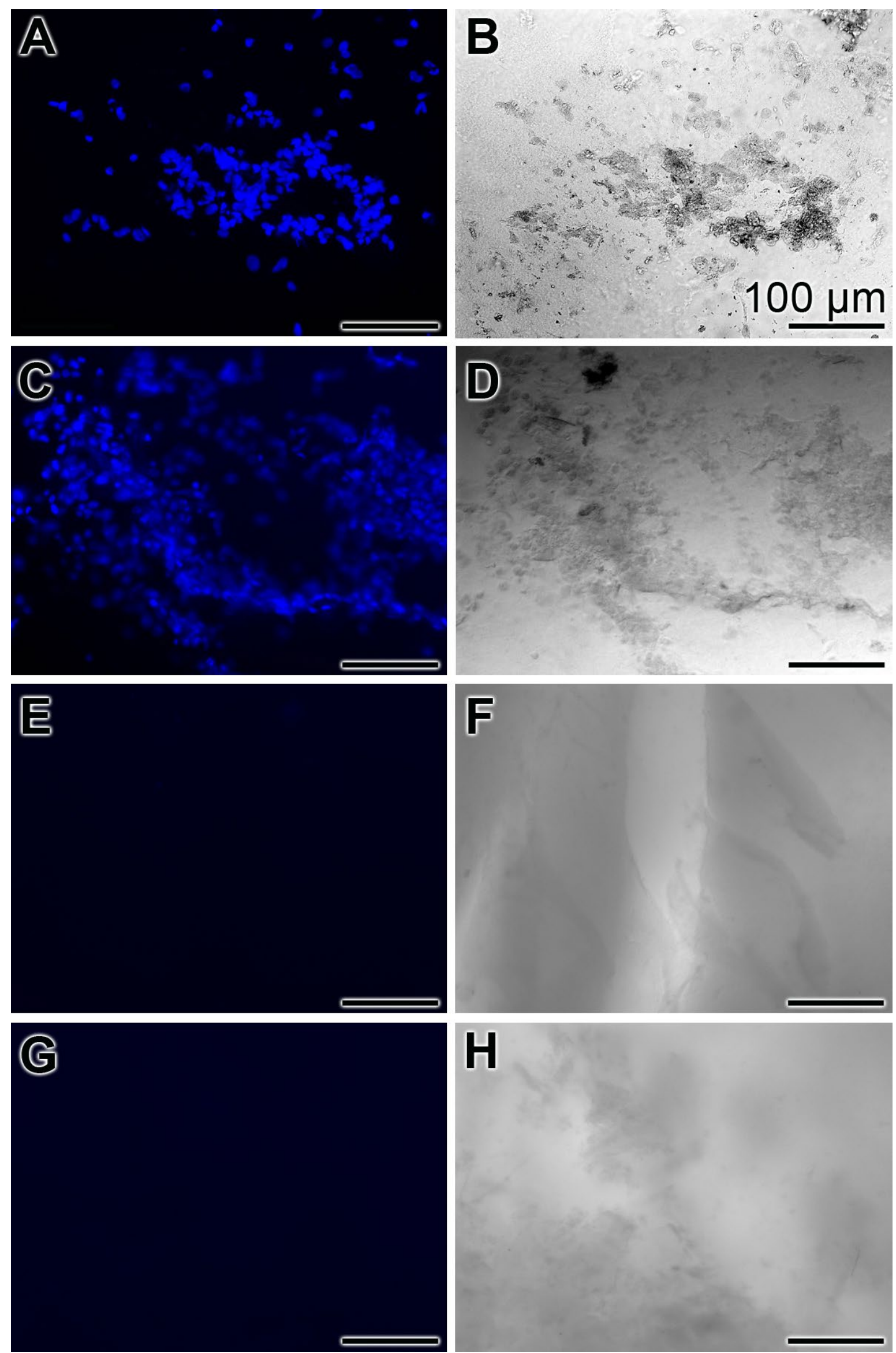

\section{H}

Fig. 7. Growth of SaOS-2 cells onto either "A-Type scaffold" (A, B and E, F) or "B-Type scaffold" (C, D and G, H). After seeding of the cells (A to D) onto the respective scaffold slices the cells were incubated for $3 \mathrm{~d}$ and then stained with DRAQ5; in controls no cells were added to the incubation assays ( $\mathbf{E}$ to $\mathbf{H}$ ). Fluorescence (left column) as well as corresponding bright field images (right column) were taken. 
pronounced compared to "A-Type scaffold". The remaining irreversible deformation after the recovery is mainly due to the loss of fluid from the material by squeezing. The latter assumption is reflected by the recordings obtained with pig cartilage (Fig. 6B). The initial strain response is much faster and already reaches the maximal strain response after $2-3 \mathrm{~s}$, with $\approx 0.23 \mathrm{~mm} / \mathrm{mm}$; the recovery curve indicates also a faster approaching of the relaxation level.

The biomechanical properties, the local hardness, follow a gradient from the surface of the scaffold to their more central regions. The mechanical stiffness, i.e. the local reduced Young's modulus of the scaffolds, was determined by nanoindentation using a ferruled optical fibre systembased nanoindenter. The surface region (thickness of about $2 \mathrm{~mm}$ ) of the "A-Type scaffold" is harder than the more central regions (about $5 \mathrm{~mm}$ from the surface) with values of $3.23 \pm 0.61 \mathrm{MPa}$ versus $0.33 \pm 0.095 \mathrm{MPa}(n=100)$. The "B-Type scaffold" shows a shell stiffness with $1.17 \pm 0.31 \mathrm{MPa}$ versus a core stiffness of $0.46 \pm 0.15 \mathrm{MPa}$ $(n=100)$. In comparison, the local Young's modulus from pig cartilage surface is $1.12 \pm 0.18 \mathrm{MPa}$, a value which is very much the same as in the artificial cartilage samples.

\section{Water content}

The water contents of the artificial cartilage scaffolds were determined by weighing before and after freeze drying. The average water content of the artificial cartilage scaffolds is $89.1 \% \pm 1.69 \%$; in turn, the resulting dry mass amounts to $10.9 \% \pm 1.69 \%(n=6)$. No differences in water content was measured between "A-Type scaffold" and "B-Type scaffold". This value matches very well with the water content of articular cartilage which amounts to $70-85 \%$ (e.g. Mansour, 2003).

\section{Growth of SaOS-2 cells and chondrocytes onto the scaffold}

In an orientating experiment, the SaOS- 2 cells were seeded $\left(2-3 \times 10^{4}\right.$ cells per $\left.\mathrm{mL}\right)$ onto either the "A-Type scaffold" or the "B-Type scaffold" and incubated for $3 \mathrm{~d}$, as described under "Materials and Methods". Then the cells remained unstained or were stained with DRAQ5 and then inspected with a digital fluorescence microscope (Fig. 7). The observation revealed that the abundance of cells onto "A-Type scaffold" is lower (Fig. 7A [fluorescence] and B [brightfield]), compared to the density which is visible onto "B-Type scaffold" (Fig. 7C and D). In a control series it is assured that both scaffolds, in the absence of any cells, did not emit any autofluorescence (Fig. 7E-H).

Based on the finding that "B-Type scaffold" provided a more suitable substrate than "A-Type scaffold" a quantitative assessment of the growth kinetics was performed. The cell growth, based on the metabolic activity, was measured with MTT reagent; both SaOS-2 cells and chondrocytes were used for the experiments. Incubation was performed in the absence or the presence of the "B-Type scaffold". The absorbance values, reflecting the MTT reaction, indicated that both the SaOS-2 cells and the chondrocytes grew with the same rate both in the absence and in the presence of the scaffold (Fig. 8). The number of doublings of SaOS-2 cells in the absence of the scaffold was 4.3 , while the chondrocytes grew more slowly.

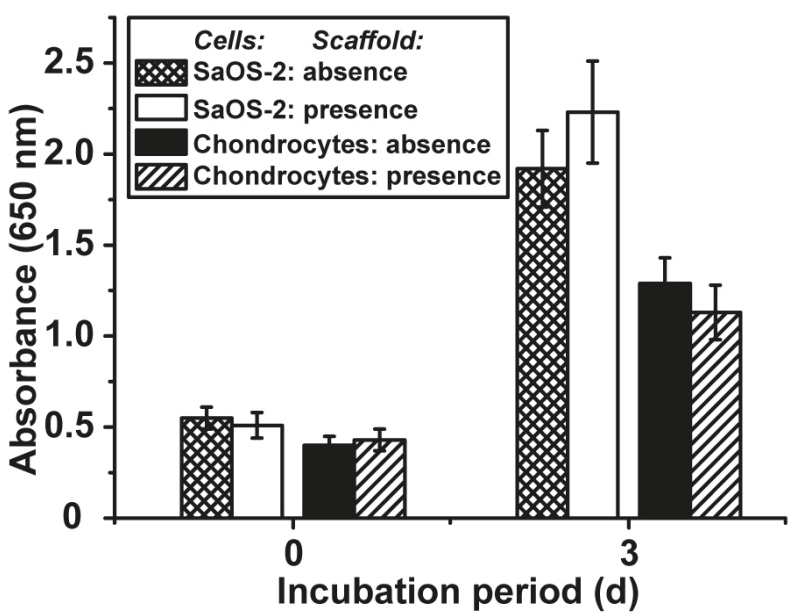

Fig. 8. Cell viability (metabolic activity) of SaOS-2 cells (cross-hatched bars and open) as well as of chondrocytes (closed bars and right hatched) after cultivation for 0 or $3 \mathrm{~d}$, respectively. The cells were seeded either in the absence (cross-hatched or closed bars) or the presence of the "B-Type scaffold" (open or right hatched bars) into the wells. After incubation, the assays were subjected to the MTT assay and the absorbance was determined at $650 \mathrm{~nm}$. Data represent means $\pm \mathrm{SD}$ of ten independent experiments.

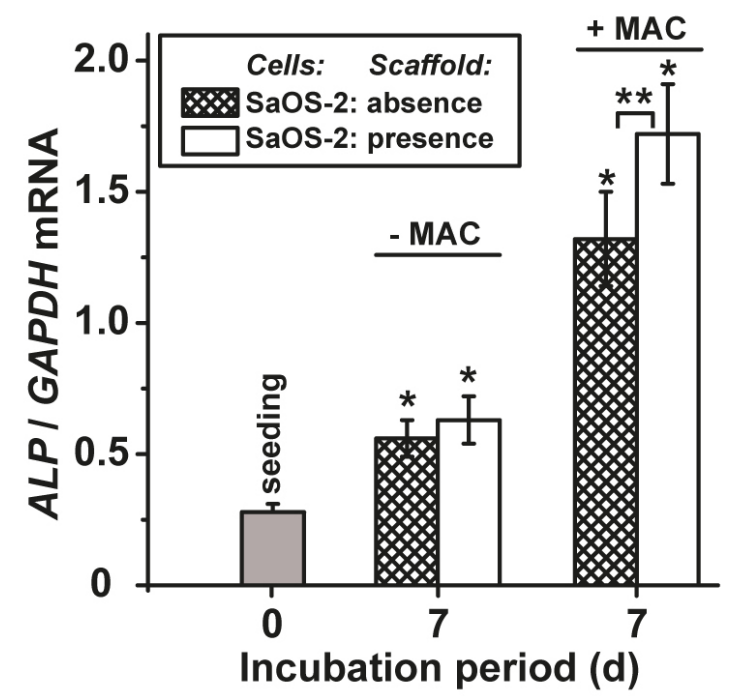

Fig. 9. Steady-state expression of the $A L P$ gene in SaOS2 cells in the absence (cross-hatched bars) or in the presence of the "B-Type scaffold" (open). After an initial incubation for $3 \mathrm{~d}$, the cell incubation was continued either in the absence or presence of the scaffold for $7 \mathrm{~d}$. The expression level at time zero (directly after seeding) is indicated with a grey-marked bar. After the indicated incubation time the cells were harvested and their RNA was extracted, which was subjected to RT-qPCR analysis. The expression values are given as ratios to the reference gene $G A P D H$. The results are means from 5 parallel experiments $\left({ }^{*} p<0.01\right)$; the values are computed against the expression measured in cells during seeding. In addition, the significance of the difference of the expression levels between the cultures incubated with MAC or without MAC is indicated (**, $p<0.01)$. 
A

Fig. 10. Response of chondrocytes to the "B-Type scaffold". The cells were incubated for $7 \mathrm{~d}$ in the absence (closed bars) or presence of the scaffold (right hatched). The levels of expression of both COL-II and aggrecan were determined by RTqPCR after an incubation period of $7 \mathrm{~d}$ and using $G A P D H . \mathrm{N}=5$ parallel experiments; ${ }^{*} p<0.01$. The significant difference of the expression levels between the cultures incubated without or with "B-Type scaffold" is marked (**, $p<0.01)$.

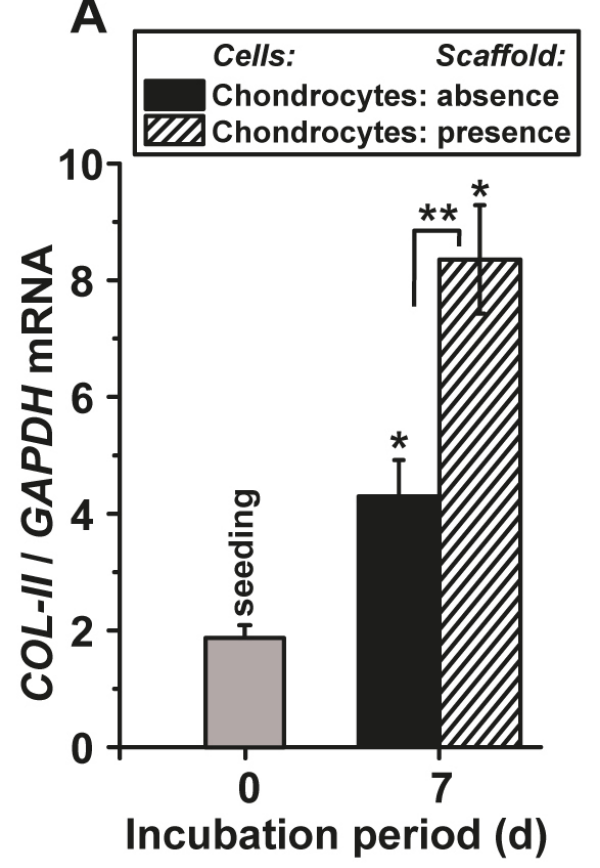

B

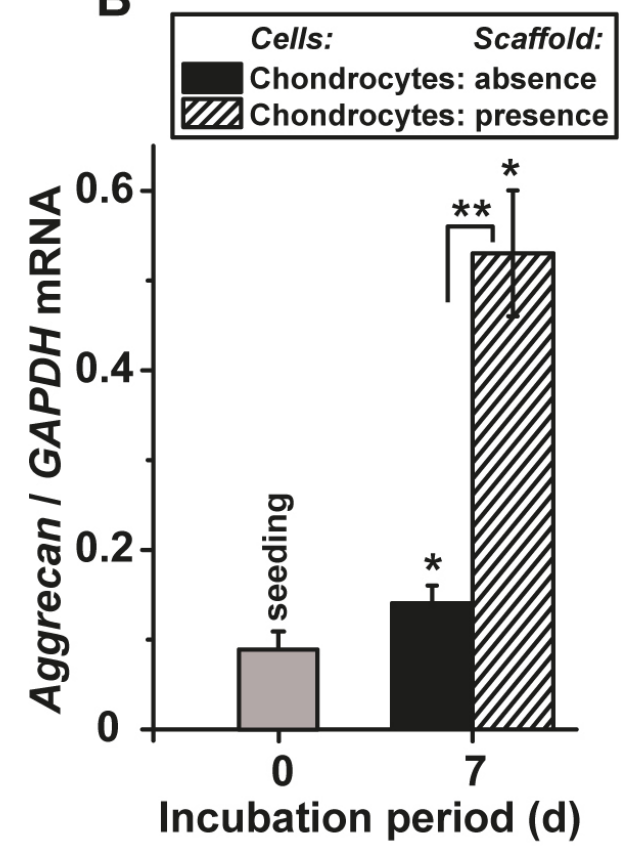

Ingrowth of chondrocytes into the scaffold

After inspection by light microscopy, the chondrocytes were found to grow into the scaffold material. After an incubation period of $2 \mathrm{~d}$ the loosely attached chondrocytes were removed and the surface of the scaffold was inspected with an optical microscope. It is seen that the considerable overall smooth surfaces are interspersed with holes into which cells are accumulated. The number of cell nests were found to be less frequent on "A-Type scaffold" (Fig. 2C) compared to "B-Type scaffold" (Fig. 2D). The number of ingrowth structures increase after an additional incubation for $2 \mathrm{~d}$ onto both scaffolds (Fig. $2 \mathbf{E}$ and $\mathbf{F}$ ). After a total incubation period of $6 \mathrm{~d}$, deeper recesses are frequently found that have diameters of up to $45 \mu \mathrm{m}$ for the "A-Type scaffold" (Fig. 2G); the depth is approximately $10 \mu \mathrm{m}$ (Fig. 2I). On the average, the hollows, containing the cells are larger and can measure up to $100 \mu \mathrm{m}$ (depth of $30 \mu \mathrm{m}$ ) for "B-Type scaffold" (Fig. 2H and J).

Effect of the scaffolds on the gene expression patterns in SaOS-2 cells and chondrocytes

The level of the $A L P$ gene expression is an indication for activation status of SaOS-2 cells (Müller et al., 2011). Here, it is shown that in the absence of the MAC the steady-state expression level of the ALP was moderately $(\approx 2$-fold with respect to the transcript level in cells during seeding), even though significantly, upregulated both in the absence or the presence of the scaffold ("B-Type scaffold" was used for this series of experiments). In contrast, if MAC was added to the cultures the upregulation was 2.4-fold higher for cells incubated without and 2.7-fold higher if the cells were treated with the scaffold for $7 \mathrm{~d}$, compared to the assays without MAC (Fig. 9). The level of induction in cells incubated with the scaffold is significantly higher, compared to the steady-state level.
In chondrocytes, the genes encoding for collagen type $I I(C O L-I I)$ as well as for aggrecan become upregulated during activation and differentiation (Vinatier et al., 2009; Flannery et al., 1998). Therefore, we determined the effect of the "B-Type scaffold" on the expression level of those two genes during an incubation period of $7 \mathrm{~d}$. The data show that during the $7 \mathrm{~d}$ incubation period a 2.2-fold induction of $C O L-I I$ is seen in untreated cells, while the scaffold elicit a 3.4-fold induction during the same period (Fig. 10A). In parallel, the chondrocytes were assayed for the expression level of aggrecan. Again, it was measured that the scaffold strongly induces the expression of this gene by 7 -fold, while in the absence of the scaffold only a 1.7-fold upregulation took place (Fig. 10B).

\section{Moulding behaviour of the scaffold for fabrication of soft tissue of a young tibia}

The tibia of a young lamb was dissected, after removal of the tissue, to the epiphysis (with its protruding intercondylar eminences) and metaphysis. These parts could be scanned independently with a laser-based 3D scanner (Fig. 11A), after which an STL was compiled (Fig. 11B). Using this file a mould, e.g. for an articular cartilage surface was prepared (Fig. 11C). Following this fabrication line both an articular cartilage surface and an epiphyseal plate could be moulded with the new scaffold (Fig. 11D). A built-up of the articular cartilage surface and the epiphyseal plate, moulded with the new cartilage, between the natural epiphysis and the metaphysis is shown (Fig. 11E). The articular cartilage surface has been formed from a mould that was computed from the scans of the epiphysis by subtraction. The resulting file was calculated and used for the fabrication of a cast into which the scaffold was injected (Fig. 11F). Hardening of the moulded scaffold was achieved after incubation in the $\mathrm{CaCl}_{2}$ solution. 

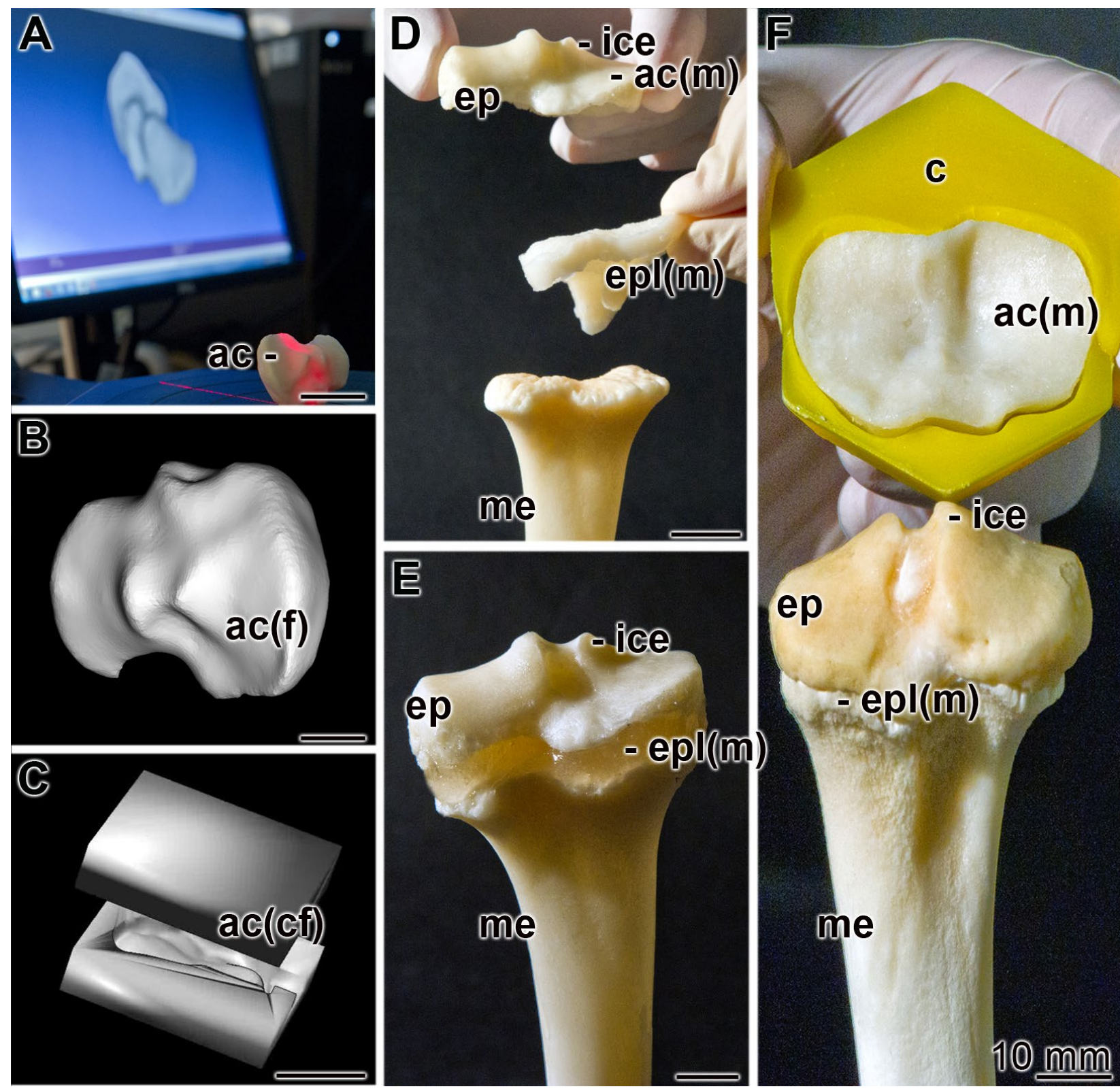

epl(m)

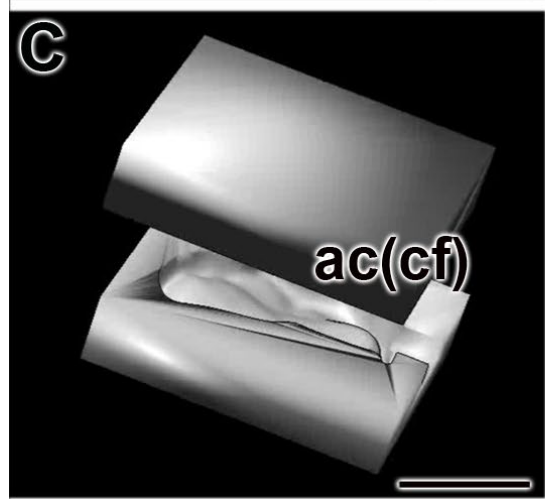

Fig. 11. Moulding of cartilage-like regions in the tibia of a young lamb $(\approx 5$ months $)$. After removal of the soft tissue the epiphysis (ep) with the protruding intercondylar eminences (ice) was removed from the metaphysis (me) along the cartilage-like epiphyseal plate (epl). The superior articular cartilage surface (ac) is layered on top of the epiphysis. (A) The hard tissue (bone) with the superficial articular cartilage surface (ac) was scanned using a laser-based 3D scanner, allowing the compilation of the (B) STL file (ac(f)). (C) After processing the file with the SolidWorks software a casting form for the articular cartilage surface (ac(cf)) was prepared. (D) The sequential regions of the tibia with the superficial articular cartilage surface, prepared by moulding with a plastic material $(\mathrm{ac}(\mathrm{m}))$, the epiphysis (ep) with the intercondylar eminences (ice), the moulded epiphyseal plate (epl(m)), and finally the metaphysis (me). (E) Placement of the parts on top of each other. (F) Fabrication of the moulded superficial articular cartilage surface with the plastic material (ac(m)). Based on the STL files a cast (c) of the superficial articular cartilage surface was calculated and the resulting form was used for moulding of the articular cartilage surface plastic (ac(m)). This layer was placed on the epiphysis (ep) with the intercondylar eminences (ice) which was put on the moulded epiphyseal plate $(\mathrm{epl}(\mathrm{m}))$, positioned onto the metaphysis.

\section{Discussion}

The physiological polymer polyP has been found in many bacterial and eukaryotic cells and also in mammalian cells, bone tissue among them (Kumble and Kornberg 1995; Schröder et al., 2000; reviewed in: Wang et al., 2015; Müller et al., 2015b). In previous studies, it has been documented that cells, isolated from bovine caudal intervertebral discs, grow readily on Ca-polyP threedimensional layers, where they express the genes encoding COL-I and COL-II (Séguin et al., 2004). These data have been extended by the finding that chondrocytes respond to polyP with an increased synthesis of glycosaminoglycan and collagen (St-Pierre et al., 2012). Recently, we have 
elaborated a fabrication process during which Na-polyP is hardened in a controlled way to tissue-like microparticles, microspheres and cubes, after exposure to divalent cations (Müller et al., 2015c); this material can be further reinforced with chitosan derivatives, e.g. N,O-CMC (Müller et al., 2015a). In turn, the polyanionic molecule, polyP, has been acknowledged as a potential bone implant material (reviewed in: Müller et al., 2015b). The potential application of polyP in orthopaedics has been further boosted by the discovery that polyP elicits an acceleration of ATP production in cells, especially if encapsulated into nanoparticles (Müller et al., 2015d).

In the present study, it is shown that polyP, together with $N, O-C M C$, can be fabricated to cartilage-like layers and even larger scaffolds that comprise not only mechanical properties similar to cartilage, especially articular cartilage, but also display morphogenetic activity to both chondrocytes and osteoblasts, the main players of chondrogenesis, especially in the calcified cartilage region (Fig. 1). The artificial scaffold prepared here displays initially (immediately after fabrication of "A-Type scaffold") a smoother texture compared to the one of a 2 d matured, more coarse material ("B-Type scaffold"). Young's modulus determination studies revealed that the stiffness of the two materials increases during 5 successive compression cycles to values that have been measured for native cartilage. These values are in agreement with published data for native cartilage, using the confined compression testing approach (Mansour, 2003). Since the local cartilage stiffness varies, depending on the size of the indents, between $0.02 \mathrm{MPa}$ (nm scale) and 2.6 MPa ( $\mu \mathrm{m}$ scale) (Stolz et al., 2004), we determined this parameter by nanoindentation technique. Using the same test parameters, the local stiffness/hardness of native pig cartilage was found to be $1.1 \mathrm{MPa}$ compared to 0.3 to $3.2 \mathrm{MPa}$ (for "A-Type scaffold") and 0.5 to 1.2 MPa ("B-Type scaffold"), respectively for the artificial scaffolds. These values, determined for the artificial polyP-based scaffold material fabricated here, agree again with those measured for native cartilage (e.g. Li et al., 2011).

Surely, quasistatic testing gives valuable insight into the mechanical properties of a given material. Our result showing that, in the repetitive compression testing approach, the Young's moduli increase with the number of cycles applied reflects a decrease in elasticity. This decrease in the viscoelastic properties during the loading/unloading treatments was found for both materials fabricated. The increment of the for "B-Type scaffold" was - like for native pig cartilage - less steep compared to the "A-Type scaffold", certainly reflecting the initial loss of water in both systems. At later phases for both scaffolds and also for the native cartilage, the strain-stress tracings reflect the largely viscoelastic properties of the materials. This explanation is supported by the recordings of the stressstrain curves during the phases of loading and unloading. With a progression of the cycle number the initial deformation during the loading phase is much lower and the creep response is less distinct. During the unloading phase, the recovery of the materials is more complete. Again, the characteristics of the artificial materials match those of the native cartilage (Mansour, 2003).
The water content in human articular cartilage varies between $76 \%$ (newborn) and $60 \%$ (elderly) individuals (Amadò et al., 1976). The material fabricated in the present study comprises approximately $90 \%$ of water. However, in consideration of our anticipated application of the material for moulding and printing purposes, we have chosen this composition since for that application a higher water content is preferable. To harden the materials and to expel the water from them can be obtained in a straightforward manner by increasing the $\mathrm{N}, \mathrm{O}-\mathrm{CMC}$ concentration during the fabrication from $5 \%$ to $10 \%[\mathrm{w} / \mathrm{v}]$; by this the water content reaches a level of $\approx 70 \%$.

Since osteochondral defects affect not only the articular cartilage but also the underlying subchondral bone layer (reviewed in: Nooeaid et al., 2012), suitable osteochondral scaffolds that meet the bio-mechanical properties of the native cartilage tissue and stimulate the regeneration of damaged cartilage as well as that of the underlying subchondral bone tissue have not yet been adequately developed. Due to the fact that the capacity of articular cartilage for regeneration and repair is extremely low (Fosang and Beier, 2011), the inclusion of a morphogenetically active polymer, e.g. polyP, into an artificial cartilage biomaterial appears to be indicated. Cartilage in general, and the calcified cartilage region in particular, comprises an hypoxic environment with an oxygen tension of 1 to $7 \%$ (see: Vinatier et al., 2009), conditions that have been recently pinpointed favourable for the polyP-triggered formation of $\mathrm{Ca}$-carbonate bioseeds onto osteoblasts, which gives rise to bone mineral formation (Müller et al., 2015e). Since cartilage is sparsely supplied with blood, and in turn also with glucose (Mansour, 2003), a polyP-based artificial cartilage would additionally provide metabolic fuel for cell metabolism (Müller et al., 2015b). By using both human bone-like SaOS-2 cells and human chondrocytes it is shown that they readily attach to both artificial materials. In order to increase the adhesion property of the polyP-based material, the His/Gly-tagged RGD peptide (Neufurth et al., 2015) was included into the material prior to its final processing step. Since the cells attach more readily to the "B-Type scaffold" in comparison to the "A-Type scaffold" the $2 \mathrm{~d}$ aged material was used for the cell and molecular biological studies. If the cells were tested in the absence or presence of the scaffold the proliferation/growth rate, based on the metabolic activity determination with MTT, was not significantly different.

To assess the morphogenetic activity of the polyP-based scaffold towards SaOS-2 cells and chondrocytes, gene expression studies have been performed using RT-qPCR. For the bone-like SaOS-2 cells the $A L P$ expression has been chosen, since the level of ALP reflects the differentiation and activation state of bone cells (Fedarko et al., 1990) and, additionally, its steady-state gene expression becomes activated after exposure to dissolved $\mathrm{Ca} / \mathrm{Na}$-polyP (Müller et al., 2011). As reported here, the scaffold material, developed here, significantly induces $A L P$ gene expression in SaOS-2 cells. First data performed in our laboratory confirm that also mesenchymal stem cells, if exposed to the mineralisation cocktail MAC, strongly express the $A L P$ gene in response to exposure to "B-Type scaffold" 
(unpublished). By this, through eliciting one key molecule (enzyme), the "B-Type scaffold" confers a required property to be essential for an artificial, biologically active cartilage scaffold (Hosseinkhani et al., 2006). Osteoblastic cells are required for building up a strong cartilage-bone (osteochondral) interface (Lu et al., 2010).

Besides matching with the suitable bio-mechanical properties of an artificial scaffold for cartilage repair, its potential either to provide or to induce the required growth factors for the chondrocytes is essential for the implant material. The inclusion of polyP to the scaffold material used here is advantageous, since this natural polymer has been shown to induce essential growth factors, e.g. BMP2, in bone cells (see "Introduction"). BMP2 is not only essential for the differentiation of bone cells but also of chondroblasts/chondrocytes (reviewed in: Vinatier et al., 2009). Besides those factors, the chondrocytes must be supplied with stimuli that induce the structural and functional extracellular scaffold materials, especially of collagen and aggrecan. COL-II is the characteristic and dominant fibrillar main collagenous component of cartilage and gives this tissue its structure and strength. Impressively the "B-Type scaffold" studied here induces the expression of this gene even 2-fold stronger than in the control system. This advantageous property of the scaffold is consolidated by the finding that also the steady-state expression of the gene aggrecan is 7-fold stronger upregulated in response to the polyP-based scaffold. Aggrecan, the major proteoglycan within the articular cartilage, functions as an integral part of the extracellular matrix of the cartilagenous tissue and confers to it its degree of compression. It provides the glyco-proteinaceous mesh for the hydrated gel structure (Kiani et al., 2002). Relevant for a regeneratively active artificial scaffold is the feature to allow the chondrocytes to grow into the material. The support and induction of the propensity of the chondrocytes to migrate into the material, as demonstrated to some extent in the present study, will contribute substantially to the overall consistency of the repaired cartilage (Schmidt et al., 2006).

Taken together, the scaffold material presented here is composed of the morphogenetically active and physiologically acting polyP. This inorganic linear polymer forms together with the biocompatible bio-polymers, alginate and $N, O-C M C$, a biomaterial with viscoelastic properties, comparable with those which are characteristic for cartilage. The material is acellular and thus will not raise ethical problems which must be considered for materials that harbour stem cells. The unique feature of this bioscaffold is its property to elicit an upregulation of the steady-state expression of genes which encode for proteins that are required for the differentiation of chondrocytes (COL-II and aggrecan) and osteoblasts (ALP). Furthermore, the material was shown to initiate ingrowth of chondrocytes into the material after a 2 to $6 \mathrm{~d}$ growth phase. A sketch, summarising the biological activity of the biomaterial to induce both bone-like cells to deposit minerals within the calcified cartilage and chondrocytes to migrate into the scaffold and express COL-II and aggrecan, is given in Fig. 1. It might be speculated that after transplantation in vitro the mesenchymal stem cells are triggered by the artificial biomaterial to differentiate into bone cells and chondrocyte. After ingrowth, the latter ones might have the capacity to form the organised collagen fibres with the proteoglycan network.

The potential to use the scaffold, described here, for the fabrication of both bone-like and cartilage-like units was proven by embedding the material into a form/mould that has been obtained by scanning and subsequent conversion of the STL file into a physical model. It is shown that both the articular cartilage surface and the epiphyseal plate can be reconstructed with the scaffold, described here, and inserted onto the epiphysis and between the epiphysismetaphysis, respectively. Based on previous data, it can be anticipated that this material which is not only biologically active (Wang et al., 2015) but also resorbable in vivo (Müller et al., 2015a) can be processed to tissue implants that are regeneratively active.

\section{Conclusion}

In the present work we describe a scaffold material, composed of the physiological polyP and the biological $N, O-C M C$ and alginate. This $N, O-C M C$-polyP-alginate hydrogel can be hardened with $\mathrm{CaCl}_{2}$ allowing the adjustment of the biomechanical properties of the material close to those which are shown by the physiological bone/ cartilage tissue. It is feasible even to use the material for manufacture of 3D solid models, custom implants, through casting into moulds that have been generated by CAD/CAM procedures. Since the material also elicits morphogenetic activity (increased expression of alkaline phosphatase, collagen and aggrecan) towards bone-like SaOS-2 cells and chondrocytes it can be anticipated that those moulded units can be used as implant in orthopaedics.

\section{Acknowledgements}

W.E.G. M. is a holder of an ERC Advanced Investigator Grant (No. 268476 BIOSILICA). This work was supported by grants from the Deutsche Forschungsgemeinschaft (Schr 277/10-3), the European Commission ("BioScaffolds: Customized Rapid Prototyping of Bioactive Scaffolds", No. 604036; and "BlueGenics": No. 311848), the International Human Frontier Science Program and the BiomaTiCS research initiative of the University Medical Center, Mainz.

\section{References}

Amadò R, Werner G, Neukom H (1976) Water content of human articular cartilage and its determination by gas chromatography. Biochem Med 16: 169-172.

Chang SC, Rowley JA, Tobias G, Genes NG, Roy AK, Mooney DJ, Vacanti CA, Bonassar LJ (2001) Injection molding of chondrocyte/alginate constructs in the shape of facial implants. J Biomed Mater Res 55: 503-511.

Chavan D, Andres D, Iannuzzi D (2011) Note: ferruletop atomic force microscope. II. Imaging in tapping mode 
and at low temperature. Rev Sci Instrum 82: 046107; doi: 10.1063/1.3579496.

Chung C, Burdick JA (2008) Engineering cartilage tissue. Adv Drug Deliv Rev 60: 243-262.

Duer MJ, Friscić T, Murray RC, Reid DG, Wise ER (2009) The mineral phase of calcified cartilage: its molecular structure and interface with the organic matrix. Biophys J 96: 3372-3378.

Fedarko NS, Bianco P, Vetter U, Robey PG (1990) Human bone cell enzyme expression and cellular heterogeneity: correlation of alkaline phosphatase enzyme activity with cell cycle. J Cell Physiol 144: 115-121.

Flannery CR, Little CB, Caterson B (1998) Molecular cloning and sequence analysis of the aggrecan interglobular domain from porcine, equine, bovine and ovine cartilage: comparison of proteinase-susceptible regions and sites of keratan sulfate substitution. Matrix Biol 16: 507-511.

Fosang AJ, Beier F (2011) Emerging frontiers in cartilage and chondrocyte biology. Best Pract Res Clin Rheumatol 25: 751-766.

Fox SAJ, Bedi A, Rodeo SA (2009) The basic science of articular cartilage: structure, composition, and function. Sports Health 1: 461-468.

Freed LE, Grande DA, Lingbin Z, Emmanual J, Marquis JC, Langer R (1994) Joint resurfacing using allograft chondrocytes and synthetic biodegradable polymer scaffolds. J Biomed Mater Res 28: 891-899.

Fuller JA, Ghadially FN (1972) Ultrastructural observations on surgically produced partial-thickness defects in articular cartilage. Clin Orthop Relat Res 86: 193-205.

Goa KL, Benfield P (1994) Hyaluronic acid. A review of its pharmacology and use as a surgical aid in ophthalmology, and its therapeutic potential in joint disease and wound healing. Drugs 47: 536-566.

Grässel S, Lorenz J. (2014) Tissue-engineering strategies to repair chondral and osteochondral tissue in osteoarthritis: use of mesenchymal stem cells. Curr Rheumatol Rep 16: 452.

Guo JF, Jourdian GW, MacCallum DK (1989) Culture and growth characteristics of chondrocytes encapsulated in alginate beads. Connect Tissue Res 19: 277-297.

Hauselmann HJ, Aydelotte MB, Schumacher BL, Kuettner KE, Gitelis SH, Thonar EJ (1992) Synthesis and turnover of proteoglycans by human and bovine adult articular chondrocytes cultured in alginate beads. Matrix 12: 116-129.

Hoemann CD, Lafantaisie-Favreau CH, Lascau-Coman V, Chen G, Guzmán-Morales J (2012) The cartilage-bone interface. J Knee Surg 25: 85-97.

Hosseinkhani H, Azzam T, Kobayashi H, Hiraoka Y, Shimokawa H, Domb AJ, Tabata Y (2006) Combination of 3D tissue engineered scaffold and non-viral gene carrier enhance in vitro DNA expression of mesenchymal stem cells. Biomaterials 27: 4269-4278.

Johnstone B, Hering TM, Caplan AI, Goldberg VM, Yoo JU (1998) In vitro chondrogenesis of bone marrowderived mesenchymal progenitor cells. Exp Cell Res 238: 265-272.

Johnstone B, Alini M, Cucchiarini M, Dodge GR, Eglin D, Guilak F, Madry H, Mata A, Mauck RL, Semino
CE, Stoddart MJ (2013) Tissue engineering for articular cartilage repair - the state of the art. Eur Cell Mater 25: 248-267.

Kang R, Zhou Y, Tan S, Zhou G, Aagaard L, Xie L, Bünger C, Bolund L, Luo Y (2015) Mesenchymal stem cells derived from human induced pluripotent stem cells retain adequate osteogenicity and chondrogenicity but less adipogenicity. Stem Cell Res Ther 6:144. doi: 10.1186/ s13287-015-0137-7.

Kato K, Eika Y, Ikada Y (1996) Deposition of hydroxyapatite thin layer onto a polymer surface carrying grafted phosphate polymer chains. J Biomed Mater Res 32: 687-691.

Kiani C, Chen L, Wu YJ, Yee AJ, Yang BB (2002) Structure and function of aggrecan. Cell Res 12: 19-32.

Kumble KD, Kornberg A (1995) Inorganic polyphosphate in mammalian cells and tissues. J Biol Chem 270: 5818-5822.

Leyhausen G, Lorenz B, Zhu H, Geurtsen W, Bohnensack R, Müller WE, Schröder HC (1998) Inorganic polyphosphate in human osteoblast-like cells. J Bone Miner Res 13: 803-812.

Li C, Allen J, Alliston T, Pruitt LA (2011) The use of polyacrylamide gels for mechanical calibration of cartilage - a combined nanoindentation and unconfined compression study. J Mech Behav Biomed Mater 4: 1540-1547.

Lu HH, Subramony SD, Boushell MK, Zhang X (2010) Tissue engineering strategies for the regeneration of orthopedic interfaces. Ann Biomed Eng 38: 2142-2154.

Ma Z, Gao C, Gong Y, Ji J, Shen J (2002) Immobilization of natural macromolecules on poly-L-lactic acid membrane surface in order to improve its cytocompatibility. J Biomed Mater Res 63: 838-847.

Mansour JM (2003) Biomechanics of cartilage. In: Kinesiology: The mechanics and pathomechanics of human movement. Oatis CA, ed. Lippincott Williams \& Wilkins, Baltimore, MD, 1992-1996.

Mara CS, Sartori AR, Duarte AS, Andrade AL, Pedro MA, Coimbra IB (2011) Periosteum as a source of mesenchymal stem cells: the effects of TGF- $\beta 3$ on chondrogenesis. Clinics (Sao Paulo) 66: 487-492.

Morrissey JH, Choi SH, Smith SA(2012) Polyphosphate: an ancient molecule that links platelets, coagulation, and inflammation. Blood 119: 5972-5979.

Mow VC, Ratcliffe A, Poole AR (1992) Cartilage and diarthrodial joints as paradigms for hierarchical materials and structures. Biomaterials 13: 67-97.

Müller WEG, Wang X, Diehl-Seifert B, Kropf K, Schloßmacher U, Lieberwirth I, Glasser G, Wiens M and Schröder HC (2011) Inorganic polymeric phosphate/ polyphosphate as an inducer of alkaline phosphatase and a modulator of intracellular $\mathrm{Ca} 2+$ level in osteoblasts (SaOS-2 cells) in vitro. Acta Biomaterialia 7: 2661-2671.

Müller WEG, Tolba E, Schröder HC, Neufurth M, Wang S, Link T, Al-Nawas B and Wang XH (2015a) A new printable and durable $\mathrm{N}, \mathrm{O}$-carboxymethyl chitosan$\mathrm{Ca}^{2+}$-polyphosphate complex with morphogenetic activity. J Mat Chem B 3: 1722-1730.

Müller WEG, Tolba E, Schröder HC and Wang X (2015b) Polyphosphate: Amorphogenetically active 
implant material serving as metabolic fuel for bone regeneration. Macromol Biosci 15:1182-1197.

Müller WEG, Tolba E, Schröder HC, Wang S, Glaßer G, Muñoz-Espí R, Link T, Wang XH (2015c) A new polyphosphate calcium material with morphogenetic activity. Materials Letters 148: 163-166.

Müller WEG, Tolba E, Feng Q, Schröder HC, Markl JS, Kokkinopoulou M and Wang X (2015d) Amorphous $\mathrm{Ca}^{2+}$ polyphosphate nanoparticles regulate the ATP level in bone-like SaOS-2 cells. J Cell Sci 128: 2202-2207.

Müller WEG, Schröder HC, Tolba E, Diehl-Seifert B, Wang XH (2015e) Mineralization of bone-related SaOS-2 cells under physiological hypoxic conditions. FEBS J 283: 74-87.

Navarro M, Michiardi A, Castaño O, Planell JA (2008) Biomaterials in orthopaedics. J R Soc Interface 5: 1137 1158.

Nehrer S, Breinan HA, Ramappa A, Hsu HP, Minas T, Shortkroff S, Sledge CB, Yannas IV, Spector M (1998) Chondrocyte-seeded collagen matrices implanted in a chondral defect in a canine model. Biomaterials 19: 23132328 .

Neufurth M, Wang X, Tolba E, Dorweiler B, Schröder HC, Link T, Diehl-Seifert B, Müller WE (2015) Modular small diameter vascular grafts with bioactive functionalities. PLoS One 10: e0133632. Doi:10.1371/ journal.pone.0133632.

Nooeaid P, Salih V, Beier JP, Boccaccini AR (2012) Osteochondral tissue engineering: scaffolds, stem cells and applications. J Cell Mol Med 16: 2247-2270.

Pal S (2014) Design of artificial human joints \& organs. Springer Science \& Business Media, New York, pp 23-40.

Pautke C, Schieker M, Tischer T, Kolk A, Neth P, Mutschler W, Milz S (2004) Characterization of osteosarcoma cell lines MG-63, Saos-2 and U-2 OS in comparison to human osteoblasts. Anticancer Res 24: 3743-3748.

Petrie A, Watson P (2013) Statistics for veterinary and animal science. Wiley-Blackwell, Oxford, pp 85-99.

Poole AR, Kojima T, Yasuda T, Mwale F, Kobayashi M, Laverty S (2001) Composition and structure of articular cartilage: a template for tissue repair. Clin Orthop Relat Res 391 Suppl: S26-S33.

Powell EO (1956) Growth rate and generation time of bacteria, with special reference to continuous culture. J Gen Microbiol 15: 492-511.

Prins HJ, Braat AK, Gawlitta D, Dhert WJ, Egan DA, Tijssen-Slump E, Yuan H, Coffer PJ, Rozemuller $\mathrm{H}$, Martens AC (2014) In vitro induction of alkaline phosphatase levels predicts in vivo bone forming capacity of human bone marrow stromal cells. Stem Cell Res 12: 428-440.

Rao NN, Gomez-Garcia MR, Kornberg A (2009) Inorganic polyphosphate: Essential for growth and survival. Annu Rev Biochem 78: 605-647.

Schmidt MB, Chen EH, Lynch SE (2006) A review of the effects of insulin-like growth factor and platelet derived growth factor on in vivo cartilage healing and repair. Osteoarthritis Cartilage 14: 403-412.

Schröder HC, Kurz L, Müller WEG, Lorenz B (2000) Polyphosphate in bone. Biochemistry (Mosc) 65: 296-303.
Séguin CA, Grynpas MD, Pilliar RM, Waldman SD, Kandel RA (2004) Tissue engineered nucleus pulposus tissue formed on a porous calcium polyphosphate substrate. Spine (Phila Pa 1976) 29: 1299-1306.

Seo JP, Tanabe T, Tsuzuki N, Haneda S, Yamada K, Furuoka H, Tabata Y, Sasaki N (2013) Effects of bilayer gelatin/ $\beta$-tricalcium phosphate sponges loaded with mesenchymal stem cells, chondrocytes, bone morphogenetic protein-2, and platelet rich plasma on osteochondral defects of the talus in horses. Res Vet Sci 95: 1210-1216.

Seo SJ, Mahapatra C, Singh RK, Knowles JC, Kim HW (2014) Strategies for osteochondral repair: Focus on scaffolds. J Tissue Eng 5: 2041731414541850. doi: 10.1177/2041731414541850.

Shafiee A, Soleimani M, Chamheidari GA, Seyedjafari E, Dodel M, Atashi A, Gheisari Y (2011) Electrospun nanofiber-based regeneration of cartilage enhanced by mesenchymal stem cells. J Biomed Mater Res A 99: 467478.

Sims CD, Butler PE, Cao YL, Casanova R, Randolph MA, Black A, Vacanti CA, Yaremchuk MJ (1998) Tissue engineered neocartilage using plasma derived polymer substrates and chondrocytes. Plast Reconstr Surg 101: 1580-1585.

Stolz M, Raiteri R, Daniels AU, VanLandingham MR, Baschong W, Aebi U (2004) Dynamic elastic modulus of porcine articular cartilage determined at two different levels of tissue organization by indentation-type atomic force microscopy. Biophys J 86: 3269-3283.

St-Pierre JP, Wang Q, Li SQ, Pilliar RM, Kandel RA (2012) Inorganic polyphosphate stimulates cartilage tissue formation. Tissue Eng Part A 18: 1282-1292.

Vinatier C, Mrugala D, Jorgensen C, Guicheux J, Noël D (2009) Cartilage engineering: a crucial combination of cells, biomaterials and biofactors. Trends Biotechnol 27: 307-314.

Wakitani S, Nawata M, Tensho K, Okabe T, Machida H, Ohgushi H (2007) Repair of articular cartilage defects in the patello-femoral joint with autologous bone marrow mesenchymal cell transplantation: three case reports involving nine defects in five knees. J Tissue Eng Regen Med 1: 74-79.

Wang XH, Schröder HC and Müller WEG (2014a) Enzymatically synthesized inorganic polymers as morphogenetically active bone scaffolds: application in regenerative medicine. Int Rev Cell Mol Biol 313: 27-77.

Wang X, Schröder HC, Schlossmacher U, Neufurth M, Feng Q, Diehl-Seifert B and Müller WE (2014b) Modulation of the initial mineralization process of SaOS-2 cells by carbonic anhydrase activators and polyphosphate. Calcif Tissue Int 94: 495-509.

Wang X, Schröder HC, Müller WE(2015) Polyphosphate as a metabolic fuel in Metazoa: A foundational breakthrough invention for biomedical applications. Biotechnol J 11: 1130 .

Weber JF, Perez R, Waldman SD (2015) Mechanobioreactors for cartilage tissue engineering. Methods Mol Biol 1340: 203-219.

Wiens M, Wang XH, Schröder HC, Kolb U, Schlossmacher U, Ushijima H, Müller WE (2010a) The 
role of biosilica in the osteoprotegerin/RANKL ratio in human osteoblast-like cells. Biomaterials 31: 7716-7725.

Wiens M, Wang XH, Schlossmacher U, Lieberwirth I, Glasser G, Ushijima H, Schröder HC, Müller WE (2010b) Osteogenic potential of biosilica on human osteoblast-like (SaOS-2) cells. Calcif Tissue Int 87: 513-524.

Zhou X, von der Mark K, Henry S, Norton W, Adams H, de Crombrugghe B (2014) Chondrocytes transdifferentiate into osteoblasts in endochondral bone during development, postnatal growth and fracture healing in mice. PLoS Genet 10: e1004820.

\section{Discussion with Reviewers}

Reviewer I: Do you have planned experiments with human bone marrow derived primary cells / stem cells and show that the artificial cartilage will stimulate the differentiation?
Authors: Surely, in the future we will apply mesenchymal stem cells (MSC) (Salinas and Anseth, 2009), having the potency to differentiate into both chondrocytes and osteoblasts, to obtain a more detailed look into the kinetics of the morphogenetic potential of the scaffold used here.

\section{Additional Reference}

Salinas CN, Anseth KS (2009) Mesenchymal stem cells for craniofacial tissue regeneration: designing hydrogel delivery vehicles. J Dent Res 88: 681-692.

Editor's Note: Scientific Editor in charge of the paper: Martin Stoddart. 